\title{
Isolation of H5N6, H7N9 and H9N2 avian influenza A viruses from air sampled at live poultry markets in China, 2014 and 2015
}

J Zhou ${ }^{12}$, J Wu W $^{3}$, X Zeng ${ }^{23}$, G Huang ${ }^{3}$, L Zou ${ }^{3}$, Y Song ${ }^{3}$, D Gopinath ${ }^{1}$, X Zhang ${ }^{3}$, M Kang ${ }^{3}$, J Lin ${ }^{3}$, BJ Cowling ${ }^{1}$, WG Lindsley ${ }^{4}$,

C Ke ${ }^{3}$, JSM Peiris ${ }^{1}, \mathrm{H}_{\text {Yen }}{ }^{1}$

1. School of Public Health, Li Ka Shing Faculty of Medicine, The University of Hong Kong, Hong Kong SAR, China

2. These authors contributed equally to this work

3. Guangdong Provincial Center for Disease Control and Prevention, Guangzhou, Guangdong, China

4. Allergy and Clinical Immunology Branch, Health Effects Laboratory Division, National Institute for Occupational Safety and Health, West Virginia, United States

Correspondence: Hui-Ling Yen (hyen@hku.hk)

Citation style for this article:

Zhou J, Wu J, Zeng X, Huang G, Zou L, Song Y, Gopinath D, Zhang X, Kang M, Lin J, Cowling BJ, Lindsley WG, Ke C, Peiris JSM, Yen H. Isolation of H5N6, H7N9 and H9N2 avian influenza A viruses from air sampled at live poultry markets in China, 2014 and 2015. Euro Surveill. 2016;21(35):pii=30331. DOI: http://dx.doi. org/10.2807/1560-7917.ES.2016.21.35.30331

Zoonotic infections by avian influenza viruses occur at the human-poultry interface, but the modes of transmission have not been fully investigated. We assessed the potential for airborne and fomite transmission at live poultry markets in Guangzhou city and in Hong Kong Special Administrative Region (SAR), China, during 2014 and 2015. Viral genome and infectious avian influenza A viruses of $\mathrm{H}_{5} \mathrm{~N} 6, \mathrm{H}_{7} \mathrm{~N} 9$, and $\mathrm{H}_{9} \mathrm{~N} 2$ subtypes were detected predominantly from particles larger or equal to $1 \mu \mathrm{m}$ in diameter in the air sampled with cyclone-based bioaerosol samplers at the live poultry markets in Guangzhou. Influenza $\mathrm{A}\left(\mathrm{H}_{9} \mathrm{~N}_{2}\right)$ viruses were ubiquitously isolated every month during the study period from air and environmental swabs, and different lineages of $\mathrm{H}_{9} \mathrm{~N}_{2}$ virus were isolated from markets where chickens and minor land-based poultry were sold. The use of de-feathering devices increased the quantity of virus-laden airborne particles while market closure reduced the amount of such particles. The results highlight the possibility of airborne transmission of avian influenza viruses among poultry or from poultry to humans within such settings. This may explain epidemiological observations in which some patients with $\mathrm{H}_{7} \mathrm{~N}_{9}$ infection reported being in markets but no direct contact with live poultry or poultry stalls.

\section{Introduction}

Influenza A viruses infect a wide range of animal species and are transmitted via virus-laden particles through multiple non-exclusive modes. Interplay between multiple viral, host and environmental factors determine influenza viral transmission efficiency [1-5]. Virus-host compatibility establishes viral tropism and the quantity of virus-laden particles that may be released from infected hosts $[1,2]$. Gravity limits the distance that virus-laden particles can travel; large droplets settle rapidly and contribute to fomite transmission while droplet nuclei less than $5 \mu \mathrm{m}$ in diameter may remain suspended in the air and mediate airborne transmission [3,4]. Humidity and temperature may impact on particle size and viability of the virus [5].

Zoonotic infections by avian influenza viruses occur at the human-avian interface [6] and live poultry markets play a critical role in maintaining, amplifying and disseminating avian influenza viruses between poultry species and from poultry to humans [7]. Exposure to live poultry has been reported by many patients with illness due to $\mathrm{H}_{5} \mathrm{~N}_{1}$ and $\mathrm{H}_{7} \mathrm{~N}_{9}$ infection, but sometimes such exposure has been indirect, for example visiting a vegetable stall within a large market where live poultry were sold [8]. Thus the modes of transmission are not well defined. The importance of contact or fomite transmission is supported by the detection of avian influenza viruses from various environmental swabs (e.g. counter surfaces, cages, water) at live poultry markets $[9,10]$. In addition, virus-laden particles that may mediate droplet or airborne transmission could be released from infected birds or as a result of aerosolgenerating procedures during poultry slaughtering at markets. Currently, however, there is no information on the quantity, particle size and viability of virus-laden particles at live poultry markets.

To systematically assess the potential modes of transmission of avian influenza viruses at the human-poultry interface, we conducted monthly air and environmental sampling during July 2014 and October 2015 at three types of live poultry markets in Guangzhou city, Guangdong Province, China, and at one wholesale market in Hong Kong Special Administrative Region (SAR), China. In Hong King SAR, a ban on keeping live poultry 
overnight at retail live poultry markets has been implemented since 2008 [7].

\section{Methods}

Samples were obtained from three different market types in Guangzhou: one wholesale market (two sites), one mixed animal market (two sites) and one retail market (one site). In Hong Kong SAR, we sampled at one wholesale poultry market.

Sampling in the Guangzhou wholesale market and mixed animal market was carried out from July 2014 to October 2015. In the retail market, sampling was conducted from January to October 2015; in the Hong Kong SAR market, sampling was carried out in October and November in 2014 and March, April, July, August, September and October in 2015.

\section{Bioaerosol and environmental sampling at live} poultry markets

Two types of cyclone-based bioaerosol samplers were used. The NIOSH bioaerosol sampler (BC251) collects particles based on their aerodynamic diameters into $>4,1-4$, and $<1 \mu \mathrm{m}$ fractions at a flow rate of $3.5 \mathrm{~L}$ per minute [11]. The NIOSH samplers were set $1.2 \mathrm{~m}$ above ground and $0.5 \mathrm{~m}$ distance from poultry housing; samplers without connection to a vacuum pump were similarly placed as negative controls. After 30 $\mathrm{min}$, a total of $0.105 \mathrm{~m}^{3}$ air was sampled; $1 \mathrm{~mL}$ of minimum essential media with $4 \%$ bovine serum albumin was added to each of the collection tubes and polytetrafluorethylene filters and transported on ice packs to the laboratories at Guangdong Provincial Center for Disease Control and Prevention or at the University of Hong Kong.

The Coriolis $\mu$ air sampler (referred hereafter to as Coriolis) (Bertin Technologies) collects air at 100-300 L per minute. After 10 min sampling using $300 \mathrm{~L}$ per minute, a total of $3.0 \mathrm{~m}^{3}$ air was sampled into a conical vial containing $5 \mathrm{~mL}$ MEM, which was concentrated using the $100 \mathrm{kDa}$ Amicon Ultra-15 (Millipore) to a final volume of $1.5 \mathrm{~mL}$. The sampler was placed $1 \mathrm{~m}$ above the ground and $0.5 \mathrm{~m}$ distance from poultry housing.

In parallel, environmental swabs were also collected from drinking water, fresh faecal droppings, or surfaces (cages, de-feathering machine and waste bins) at the markets. Temperature and humidity were recorded using a hygro-thermometer (Extech).

\section{Detection and quantification of influenza viral} RNA genome

Viral RNA for testing by quantitative real-time reverse transcription polymerase chain reaction (qRRT-PCR) was extracted from $400 \mu \mathrm{L}$ of the specimen using the QIAGEN EZ Robot or the RNeasy Mini Kit (Qiagen) and eluted into $60 \mu \mathrm{L} \mathrm{H} \mathrm{H}_{2} \mathrm{O}$. Influenza viral RNA was detected using AgPath-ID One-Step RT-PCR Reagents (Life Technologies) with specific primers and probes [12], using $5 \mu \mathrm{L}$ of the eluted RNA. The number of influenza
$A$ virus $M$ gene copies per $m^{3}$ air was calculated, where $V_{w}$ is the volume of medium added to the sampler, $V_{r}$ is the volume of specimen used for RNA extraction, $U$ is the airflow rate ( $\mathrm{m}^{3}$ per minute) and $\mathrm{t}$ is the sampling time.

\section{Formula 1}

$M$ gene copies per cubic metre air $=$ copies per $\mu \mathrm{L} \times 60 \mu \mathrm{L} \times \mathrm{VwVr} \div(\mathrm{U} \times \mathrm{t})$

The minimum linear range of quantification (LoQ) was two copies $M$ gene per $\mu \mathrm{L}$, and the LoQs were determined as 2,857 and 150 copies $/ \mathrm{m}^{3}$ air for the NIOSH and Coriolis samplers, respectively. Influenza $A$ virus $M$ gene-positive samples were subtyped using $\mathrm{H}_{5}$, $\mathrm{H}_{7-}$ or $\mathrm{H}$ 9-specific primers and probes by qRRT-PCR [9].

\section{Virus isolation in embryonated chicken eggs}

All samples with threshold cycle $(\mathrm{Ct})$ values $\leq 35$ for influenza $A$ virus $M$ gene by qRRT-PCR were propagated in embryonated chicken eggs by injecting $0.2 \mathrm{~mL}$ of specimen into the allantoic cavity and incubated at $37^{\circ} \mathrm{C}$ for $48-72$ hours. Allantoic fluid that agglutinated chicken or turkey red blood cells were further characterised by qRRT-PCR; samples with increasing copy numbers for influenza viral $\mathrm{H}_{5}, \mathrm{H}_{7}$ or $\mathrm{H}_{9}$ gene (reduced $\mathrm{Ct}$ values relative to the original field samples) after egg propagation were considered positive by virus isolation.

Genome sequencing and phylogenetic analysis Viral RNA from an isolated virus was extracted using the RNeasy Mini Kit (Qiagen), amplified by RT-PCR [13] and was subjected to dideoxynucleotide sequencing or next-generation sequencing using the Ion PGM System with PathAmp FluA Reagents (Life Technologies). The sequences were submitted to the Global Initiative on Sharing All Influenza Data (GISAID) [14] (EPI674320, EPI674374 to EPI674424, EPI676397 to EPI676400, EPI676490, EPI676491, EPI696727 and EPI696728). Phylogenetic analysis was performed with the $\mathrm{H} 9$ haemagglutinin (HA) coding sequence $(1,093 \mathrm{nt}, 115-1,207$ nt from ATG) aligned with reference strains from GISAID (Table 1). Phylogenetic trees were constructed by maximum likelihood method with bootstrap analysis $(n=1,000)$ by MEGA (version 6.0).

Statistical analysis

Correlation analyses were done by determining Spearman's rank-correlation coefficients $\left(r_{s}\right)$. Fisher's exact test was applied to assess if the subtypes detected were statistically significantly different. Statistical analyses were performed using Graphpad Prism 6.0.

\section{Ethics statement}

Permission from the vendors at the poultry markets was obtained before the bioaerosol and environmental sampling. All sampling was performed without 


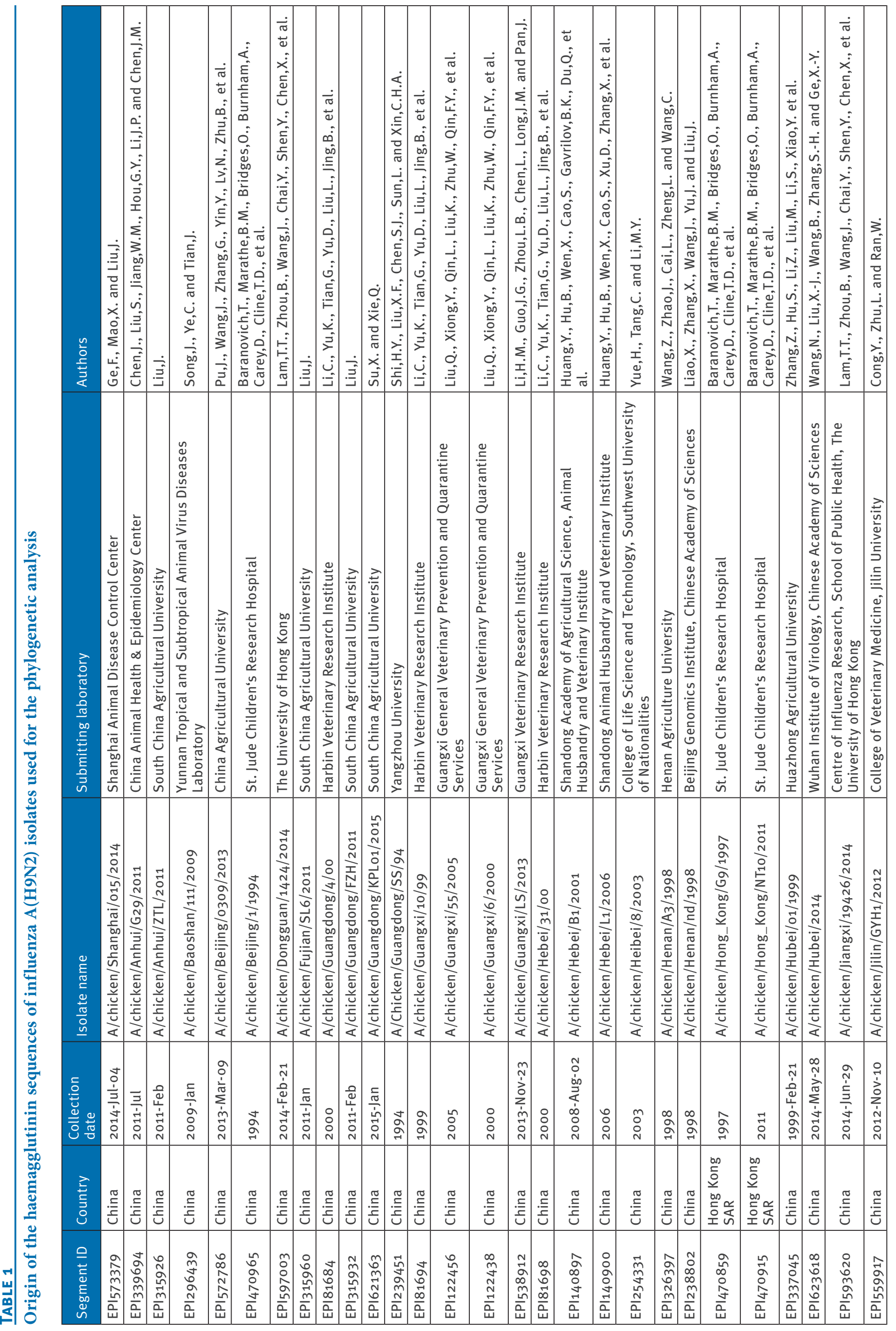




\begin{tabular}{|c|c|c|c|c|c|c|c|c|c|c|c|c|c|c|c|c|c|c|c|c|c|c|}
\hline & 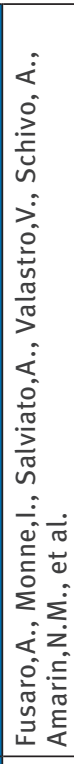 & 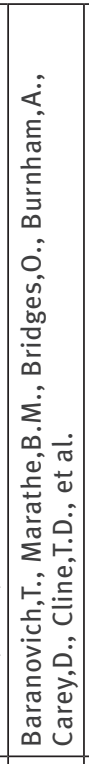 & 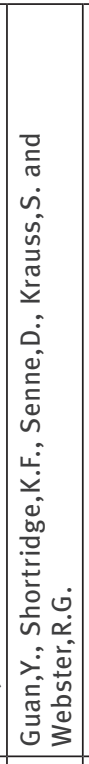 & $\begin{array}{l}\dot{0} \\
\dot{0} \\
\underline{0}\end{array}$ & 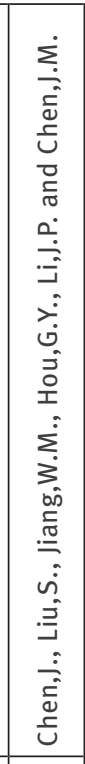 & 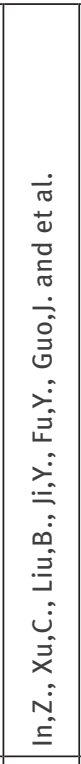 & 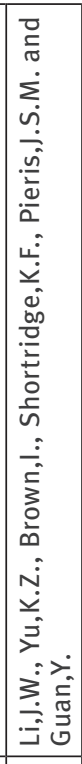 & 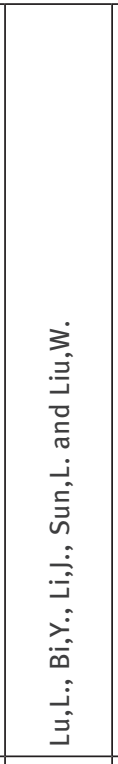 & 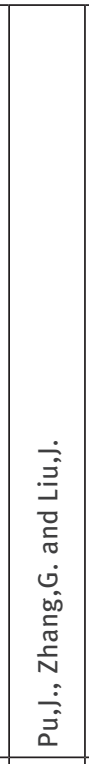 & 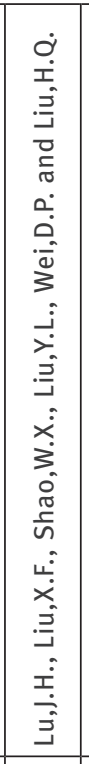 & 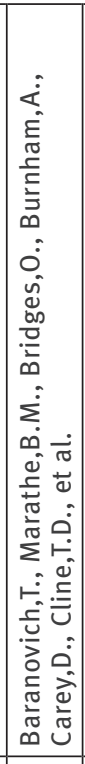 & 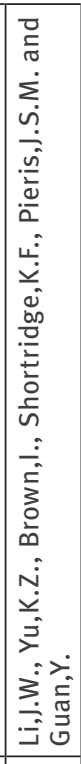 & 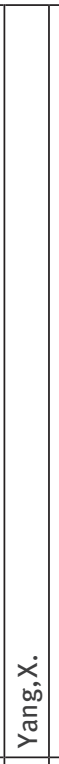 & 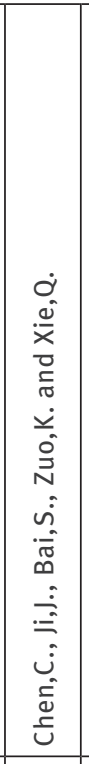 & 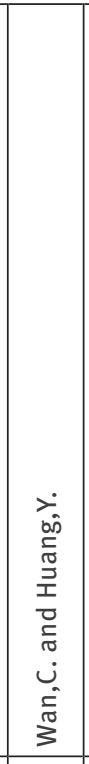 & 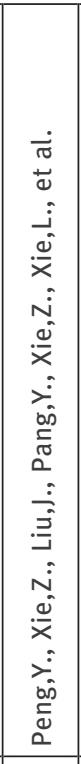 & 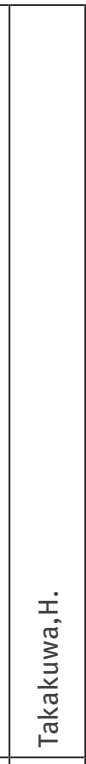 & 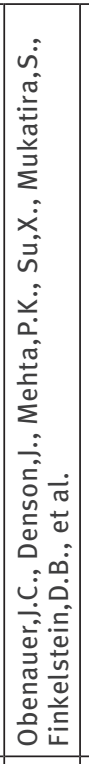 & 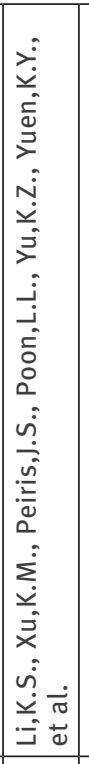 & 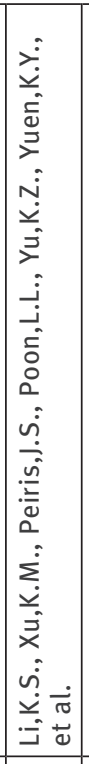 & 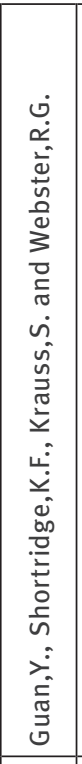 & 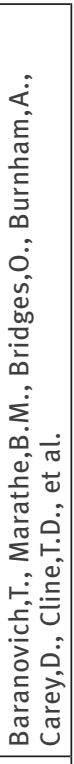 \\
\hline & 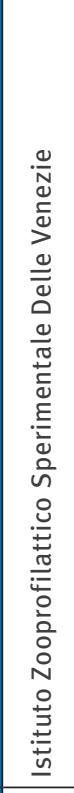 & 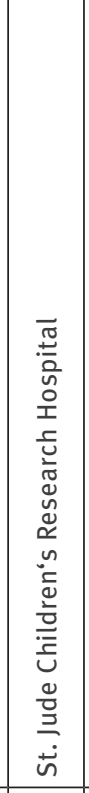 & 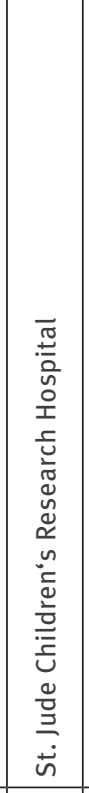 & 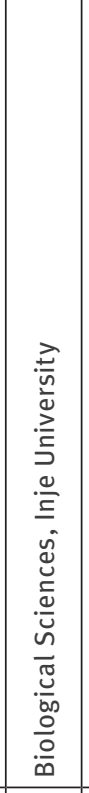 & 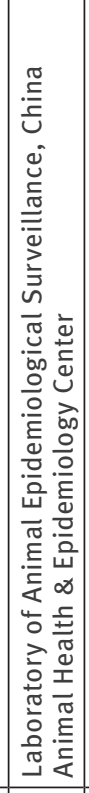 & 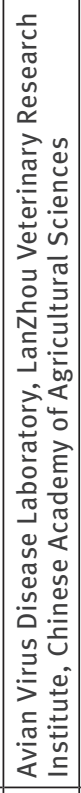 & 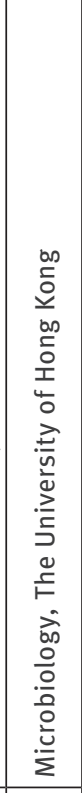 & 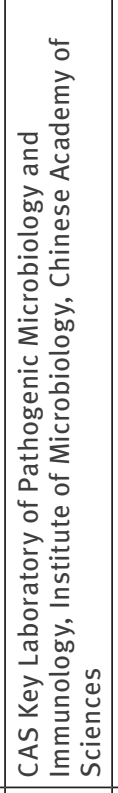 & 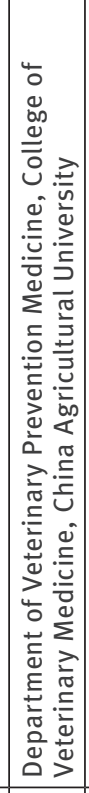 & 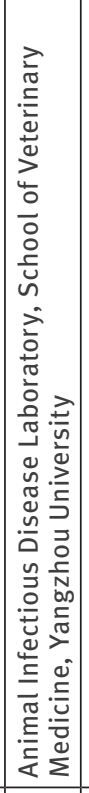 & 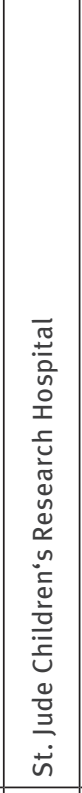 & 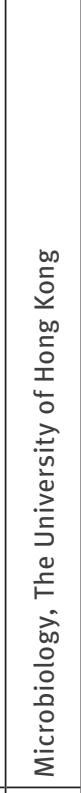 & 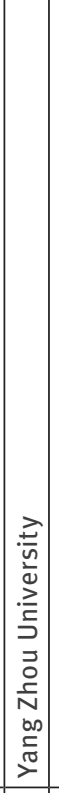 & 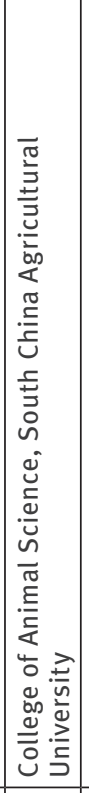 & 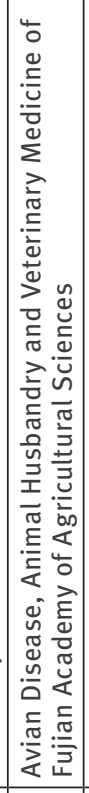 & 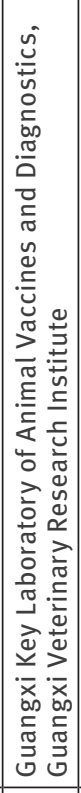 & 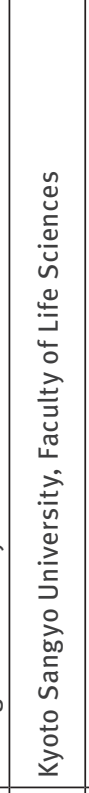 & 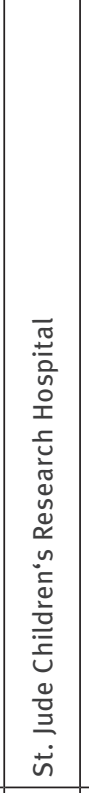 & 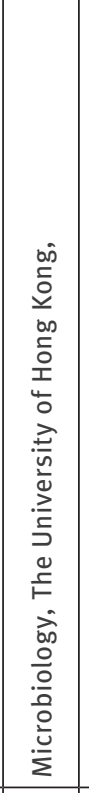 & 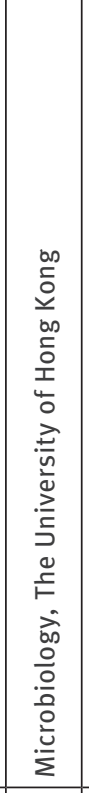 & 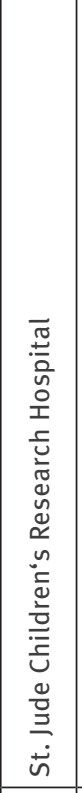 & 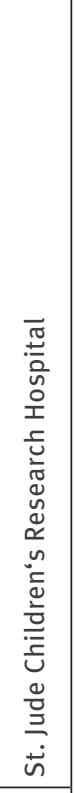 \\
\hline & 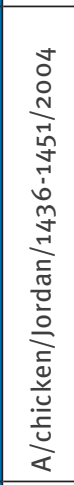 & 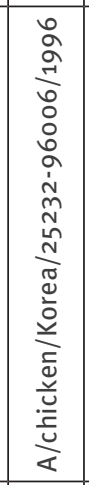 & 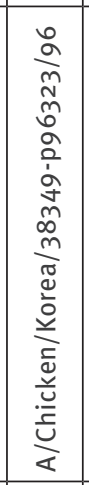 & 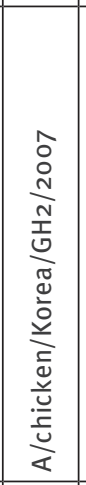 & 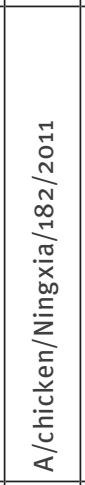 & 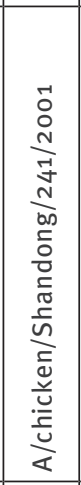 & 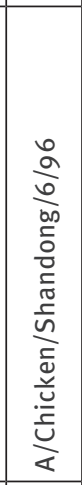 & 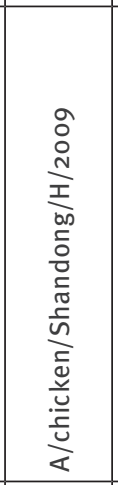 & 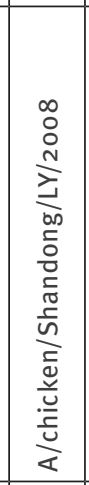 & 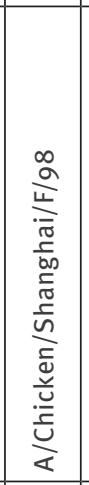 & 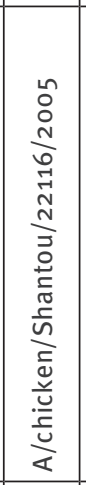 & 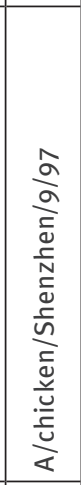 & 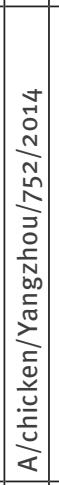 & 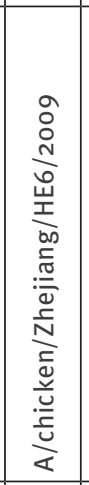 & 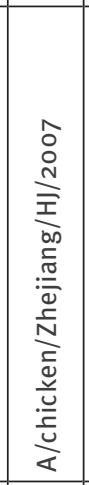 & 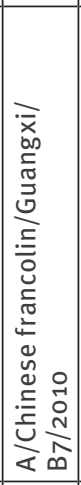 & 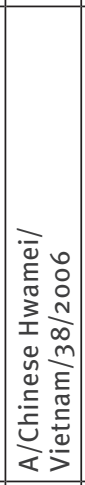 & 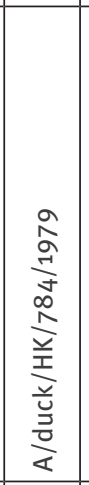 & 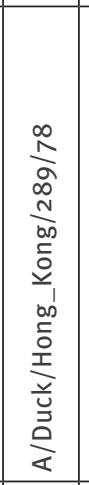 & 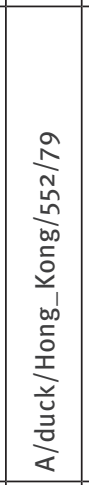 & 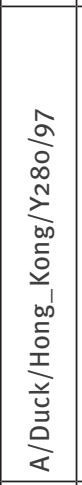 & 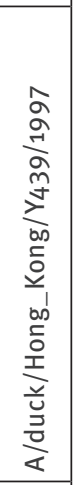 \\
\hline & $\begin{array}{l}\text { ¿े } \\
\text { ¿ } \\
\end{array}$ & ڤั & $\stackrel{\text { वे }}{\circ}$ & 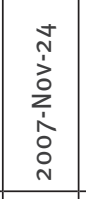 & 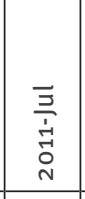 & 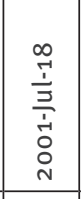 & $\begin{array}{l}\text { ڤे } \\
\text { - }\end{array}$ & 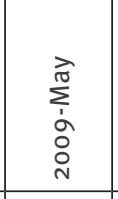 & 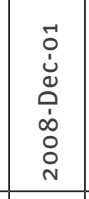 & $\begin{array}{l}\infty \\
\stackrel{\sigma}{-}\end{array}$ & $\begin{array}{l}\text { on } \\
\vdots \\
\text { Non }\end{array}$ & बे & 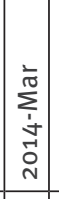 & 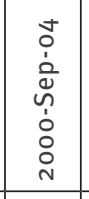 & $\begin{array}{l}\hat{o} \\
\vdots \\
\text { N }\end{array}$ & $\begin{array}{l}\stackrel{0}{1} \\
\dot{\Delta} \\
0 \\
\dot{0} \\
\dot{0} \\
\stackrel{N}{ }\end{array}$ & 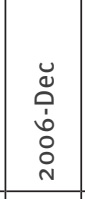 & 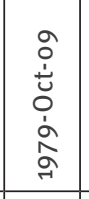 & $\begin{array}{l}\text { ô } \\
\stackrel{N}{2}\end{array}$ & مે & बे & aे \\
\hline & $\begin{array}{l}\frac{5}{0} \\
\text { 흠 }\end{array}$ & 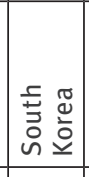 & 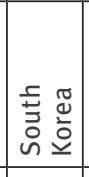 & 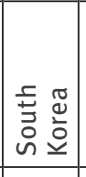 & .气 & : & : & : & : & : & : & . & 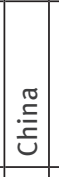 & 总 & 疍 & 葛 & 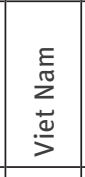 & 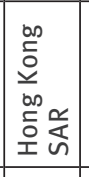 & 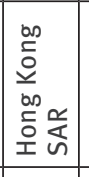 & 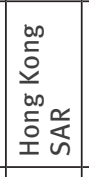 & 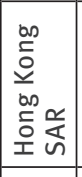 & 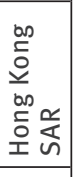 \\
\hline 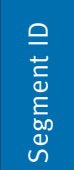 & 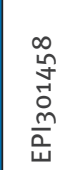 & 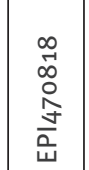 & $\begin{array}{l}\overrightarrow{0} \\
\hat{\alpha} \\
\frac{\omega}{4}\end{array}$ & 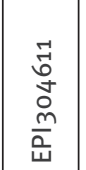 & 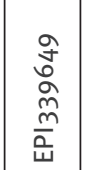 & 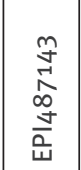 & 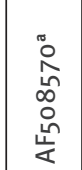 & 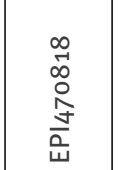 & 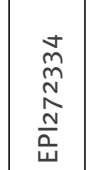 & $\begin{array}{l}\tilde{N} \\
\vdots \\
\text { Oे } \\
\frac{\tilde{N}}{\tilde{U}}\end{array}$ & 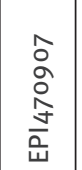 & 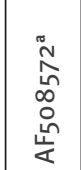 & $\mid \begin{array}{l}0 \\
\stackrel{0}{0} \\
\hat{n} \\
\frac{\hat{n}}{\omega} \\
\end{array}$ & 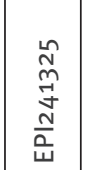 & 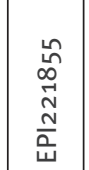 & 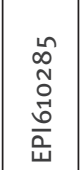 & 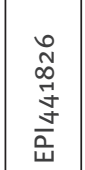 & $\begin{array}{l}\tilde{N} \\
\hat{0} \\
\stackrel{0}{0} \\
\stackrel{0}{0}\end{array}$ & 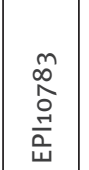 & 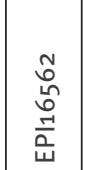 & $\begin{array}{l}0 \\
\infty \\
\infty \\
\frac{\omega}{4} \\
\frac{\omega}{4}\end{array}$ & 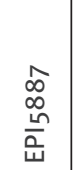 \\
\hline
\end{tabular}




\begin{tabular}{|c|c|c|c|c|c|c|c|c|c|c|c|c|c|c|c|c|c|}
\hline & 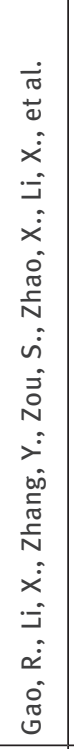 & 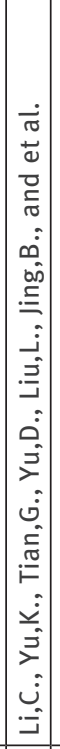 & 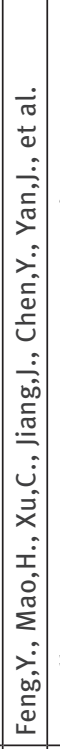 & 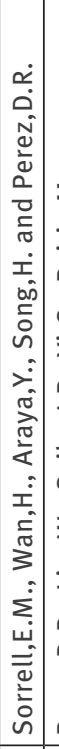 & 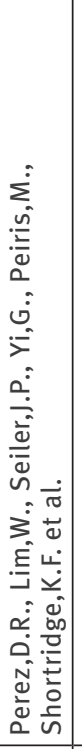 & 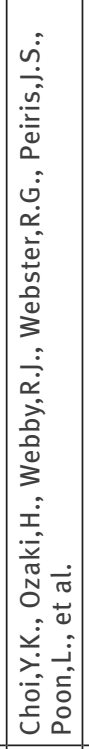 & 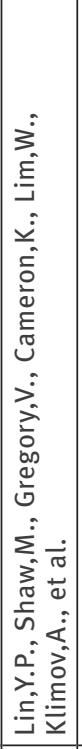 & 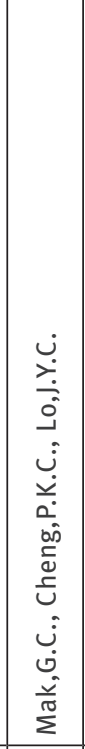 & 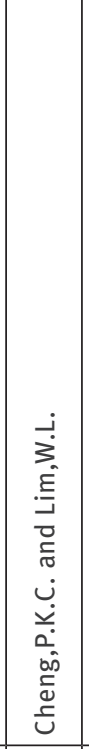 & 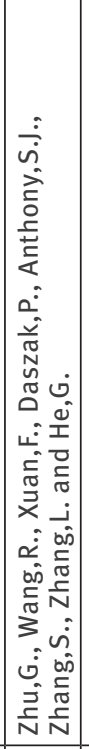 & 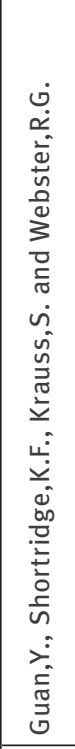 & 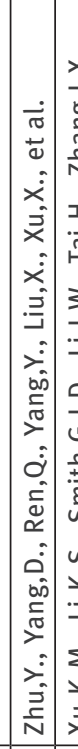 & 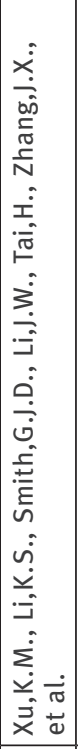 & 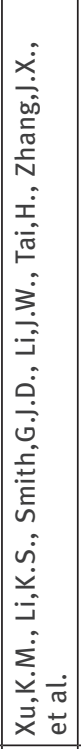 & 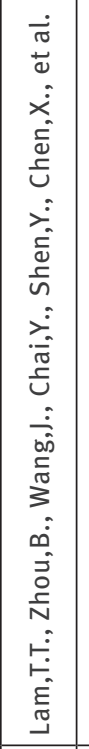 & 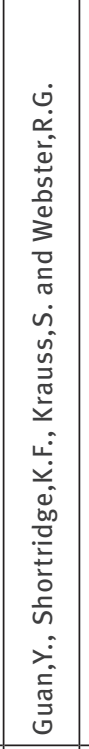 & 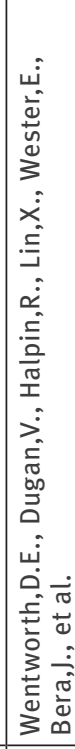 \\
\hline & 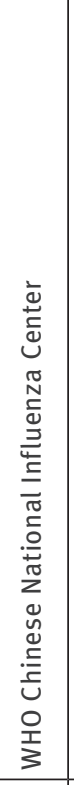 & 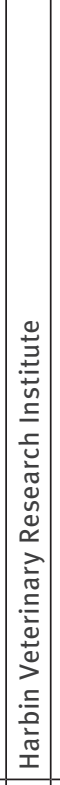 & 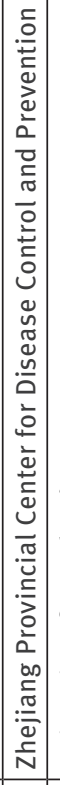 & 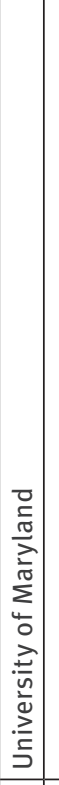 & 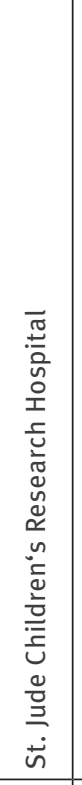 & 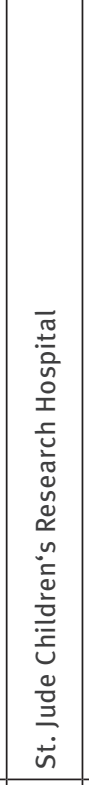 & 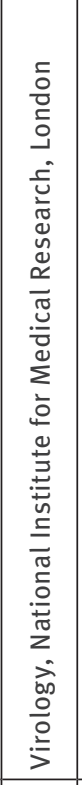 & 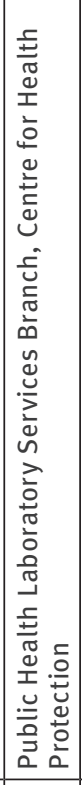 & 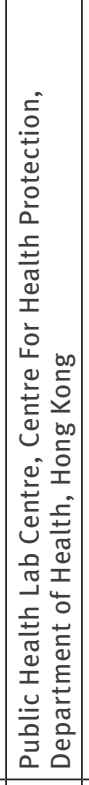 & 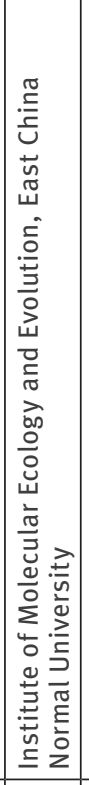 & 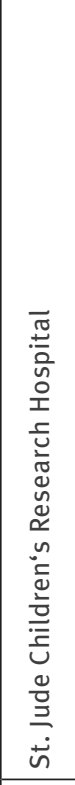 & 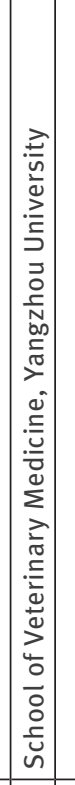 & 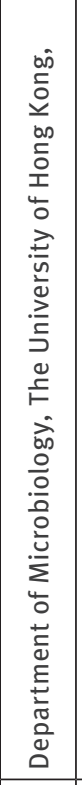 & 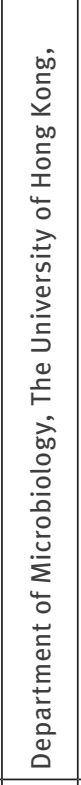 & 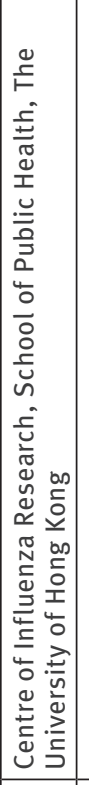 & 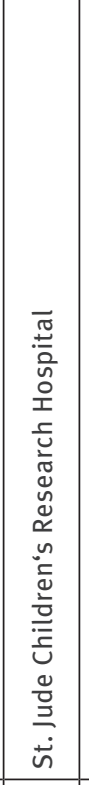 & 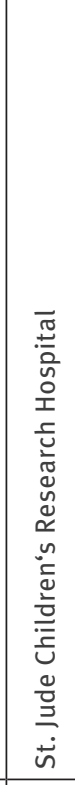 \\
\hline & 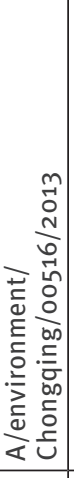 & 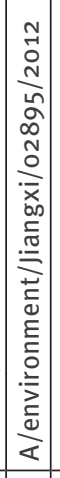 & 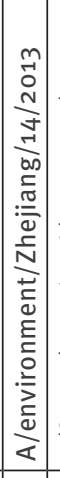 & 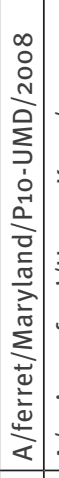 & 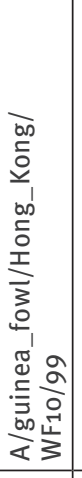 & 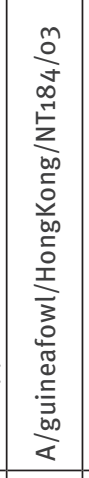 & 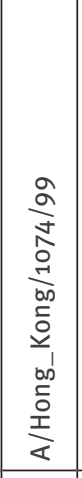 & 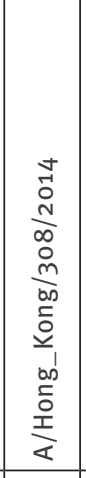 & 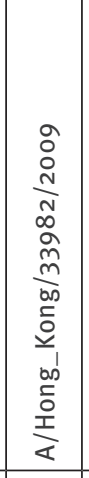 & 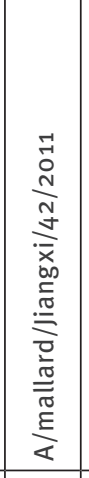 & 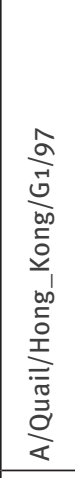 & 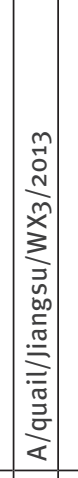 & 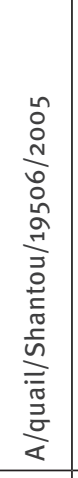 & 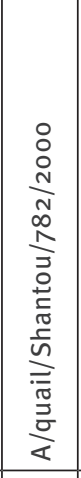 & 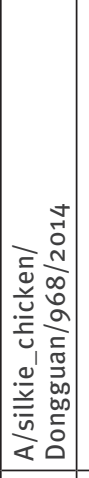 & 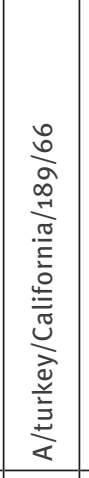 & 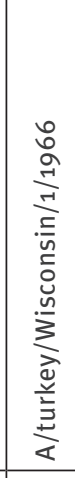 \\
\hline & 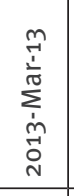 & & 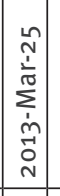 & : & बे & $\begin{array}{l}\text { ô } \\
\stackrel{i}{N}\end{array}$ & $\begin{array}{l}\text { बे } \\
\text { ने }\end{array}$ & 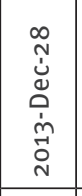 & 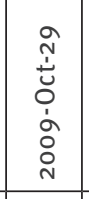 & 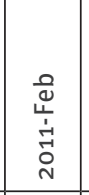 & बे & 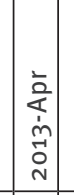 & $\begin{array}{l}n \\
\stackrel{0}{0} \\
\text { N }\end{array}$ & $\therefore$ & $\begin{array}{l}\vec{N} \\
\dot{d} \\
\dot{\omega} \\
\dot{4} \\
\dot{0} \\
\stackrel{N}{0}\end{array}$ & 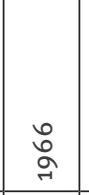 & $\begin{array}{l}\circ \\
\stackrel{్}{\circ}\end{array}$ \\
\hline & 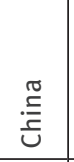 & 言 & 言 & 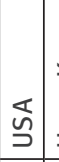 & 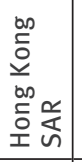 & 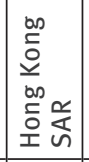 & 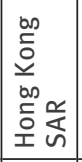 & 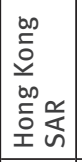 & 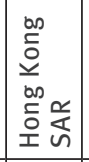 & 总 & 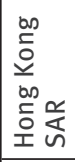 & 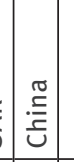 & $\stackrel{\frac{\sigma}{5}}{\underline{E}}$ & : & 昙 & 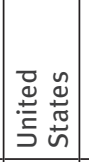 & 受吾 \\
\hline$\xi$ & $\begin{array}{l}\tilde{a} \\
\frac{1}{\alpha} \\
\frac{a}{a} \\
\frac{a}{\omega}\end{array}$ & 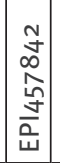 & 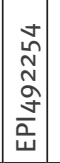 & 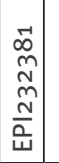 & 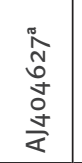 & 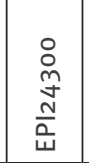 & 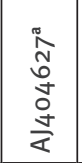 & $\begin{array}{l}m \\
0 \\
0 \\
o \\
\frac{a}{a} \\
\frac{1}{4}\end{array}$ & 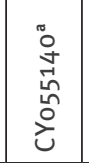 & 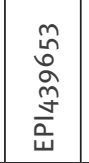 & 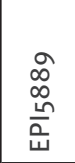 & $\left|\begin{array}{c}0 \\
\hat{\omega} \\
\hat{\omega} \\
\frac{\hat{\omega}}{\omega} \\
\omega\end{array}\right|$ & 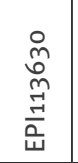 & 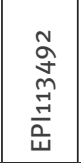 & $\begin{array}{l}\frac{7}{5} \\
\text { 点 } \\
\frac{2}{4}\end{array}$ & $\frac{\hat{\sigma}}{\omega}$ & 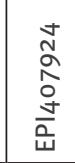 \\
\hline
\end{tabular}


directly handling the poultry, thus animal ethics were not applicable for our study.

\section{Results}

Sampling at a wholesale market in Guangzhou The wholesale market was organised into areas for holding live poultry, slaughtering and selling dressed poultry (poultry carcasses). Two sites were sampled. Site A1 was within the live poultry holding area of ca $5,500 \mathrm{~m}^{2}$, where $10,000-20,000$ poultry (predominantly chickens) were kept at any one time. Chickens were kept on a litter-bedded floor and were often sold to other retail markets within three days. Site A2 was a stall for chicken slaughtering with a de-feathering machine. There was one routinely scheduled market rest day per month; additional rest days may be

\section{FIGURE 1}

Influenza $\mathrm{A}$ virus $\mathrm{M}$ gene copy number from particles in air sampled at a wholesale live poultry market in Guangzhou city, China, July 2014-October 2015
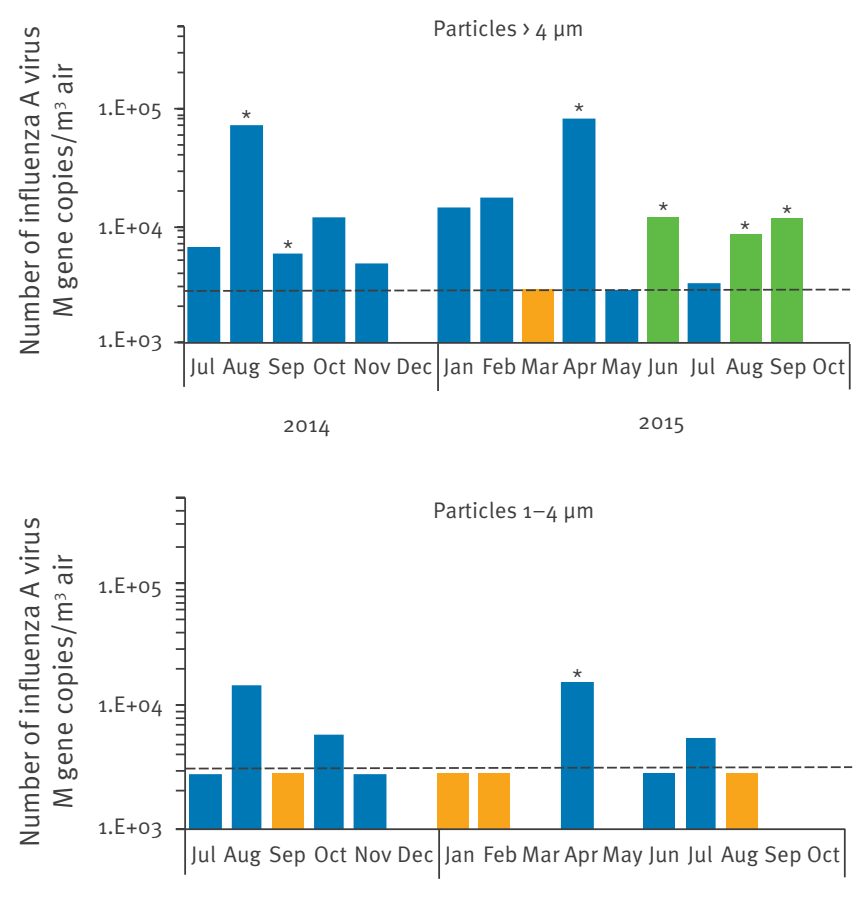

2014

2015

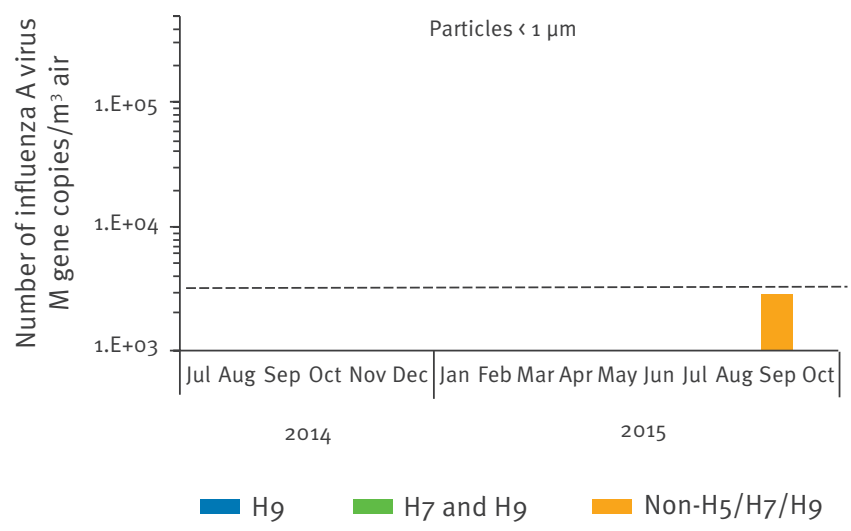

scheduled in response to reports of human zoonotic infections.

Site A1

Using the NIOSH sampler, influenza A virus $M$ gene was detected by qRRT-PCR from particles $>4 \mu \mathrm{m}$ in $14 / 16$ samples at 3,300-79,357 copies $/ \mathrm{m}^{3}$ air, with 2/14 samples positive for the $M$ gene but below the LoQ. In addition, the $M$ gene was detected from particles 1-4 $\mu \mathrm{m}$ in $11 / 16$ samples at $5,578-15,536$ copies/m $/ \mathrm{m}^{3}$ air $(7 / 11$ below LoQ) and from particles $<1 \mu \mathrm{m}(1 / 16$ sampling, 1/1 below LoQ) (Figure 1). In parallel, NIOSH samplers without a connection to a vacuum pump (as negative controls) were consistently negative for influenza A virus $M$ gene by qRRT-PCR from particles $>4,1-4$ or $<1$ $\mu \mathrm{m}$. H9 was the predominant HA subtype detected by qRRT-PCR, while mixed $\mathrm{H}_{7}$ and $\mathrm{H}_{9}$ or non $-\mathrm{H}_{5} / \mathrm{H}_{7} / \mathrm{H}_{9}$ RNA were also detected (Figure 1, Table 2).

The quantity and subtypes of influenza virus-laden particles detected in the air using a NIOSH bioaerosol sampler, at particle sizes of $>4,1-4$ and $<1 \mu \mathrm{m}$ diameter are shown. The horizontal dotted lines indicate the linear range of quantification for the influenza $A$ virus $M$ gene by quantitative real-time reverse transcription polymerase chain reaction (qRRT-PCR) assay. Samples in which virus was isolated after egg passage are indicated by an asterisk (*).

$\mathrm{H}_{9} \mathrm{~N}_{2}$ viruses (five isolates) and mixture of $\mathrm{H}_{7} \mathrm{~N}_{9} / \mathrm{H}_{9} \mathrm{~N}_{2}$ viruses (one isolate) were further isolated from the air samples collected by the NIOSH sampler at the fraction of > $4 \mu \mathrm{m}$, with an isolation rate (number of isolates/ number of PCR-positive samples) of 6/14 (Tables 2 and 3). From the fraction of $1-4 \mu \mathrm{m}$, one $\mathrm{H}_{9} \mathrm{~N}_{2}$ virus was isolated from 11 influenza $A$ virus $M$ gene-positive samples after egg propagation (Table 2).

The HA and neuraminidase (NA) genes of the sample with mixed $\mathrm{H}_{7} \mathrm{~N}_{9}$ and $\mathrm{H}_{9} \mathrm{~N}_{2}$ (A/Environment-air/GZ/ NIOSH-395/2015) from our study showed $99.3 \%$ and $99.6 \%$ homology to that of the A/Chicken/Guangdong/ GZo68/15 (H7N9) virus (GISAID:EPI_ISL_176834), respectively.

The Coriolis air sampler showed comparable efficiency to the NIOSH sampler in detecting influenza A virus $M$ gene in the air samples, with Spearman's $r_{s}=0.68$ $(p=0.01)$. Influenza A virus $M$ gene was detected from 12 of 14 samples at 310-21,413 copies/m³ air (Table 2). Four $\mathrm{H}_{9} \mathrm{~N}_{2}$ viruses were isolated after one passage in embryonated eggs from 12 influenza $A$ virus $M$ genepositive Coriolis samples, including one that was originally positive for both $\mathrm{H}_{9}$ and $\mathrm{H}_{7}$ RNA by qRRT-PCR (Tables 2 and 3 ).

Influenza A virus $M$ gene was detected in 36 of 59 environmental swabs - with a total isolation rate of $15 / 36$ - including drinking water, faecal droppings and surfaces (Table 2). Of samples that were influenza $A$ virus $M$ gene-positive, further subtyping demonstrated the 
H9 subtype (19/36), mixed $\mathrm{H}_{7} / \mathrm{H}_{9}(14 / 36)$ and non- $\mathrm{H}_{5} /$ $\mathrm{H} 7 / \mathrm{H} 9$ specimens (3/36). A total of $12 \mathrm{HgN} 2$ viruses and three mixtures of $\mathrm{H}_{7} \mathrm{~N}_{9} / \mathrm{H}_{9} \mathrm{~N}_{2}$ viruses were isolated (Table 2 and 3). The distribution of virus subtypes detected in the environmental swabs and the NIOSH air samplers were not significantly different $(p=0.51$, Fisher's exact test).
We analysed if viral load or environmental conditions might be associated with virus isolation from the air samplers; however, the $M$ gene copy numbers, temperature, and relative humidity were not significantly different between months in which virus was isolated and those in which it was not, using the NIOSH sampler ( $p=0.17,0.07$ and 0.72 , respectively, Mann-Whitney

\section{TABLE 2}

Influenza A viruses detected and isolated from air and environmental samples at live poultry markets, Guangzhou, China (3 markets), and Hong Kong SAR (1 market), July 2014-October 2015

\begin{tabular}{|c|c|c|c|c|c|c|c|c|c|}
\hline \multirow[b]{2}{*}{ Market and sample type } & \multirow{2}{*}{$\begin{array}{l}\text { Number of } \\
\text { influenza A } \\
\text { virus } M \text { gene- } \\
\text { positive } / \\
\text { total sampled }\end{array}$} & \multirow{2}{*}{$\begin{array}{c}\text { Number of isolates/ } \\
\text { number of influenza A } \\
\text { virus } \\
\text { M gene-positive } \\
\text { samplesc }\end{array}$} & \multicolumn{7}{|c|}{$\begin{array}{c}\text { HA subtype of influenza } A \text { virus } M \text { gene-positive samples }{ }^{d} \\
\text { (number of isolates) }\end{array}$} \\
\hline & & & $\mathrm{H}_{5}$ & $\mathrm{H}_{7}$ & H9 & $\begin{array}{l}\mathrm{H}_{5} \\
\text { and } \\
\mathrm{H}_{9}\end{array}$ & $\begin{array}{c}\mathrm{H}_{7} \\
\text { and } \\
\mathrm{H}_{9}\end{array}$ & $\begin{array}{l}\mathrm{H}_{5} \\
\text { and } \\
\mathrm{H}_{7}\end{array}$ & Non- $\mathrm{H}_{5} / \mathrm{H}_{7} / \mathrm{H}_{9}$ \\
\hline \multicolumn{10}{|l|}{ Wholesale market, Guangzhou e } \\
\hline \multicolumn{10}{|l|}{ Air (NIOSH sampler) } \\
\hline Particles $>4 \mu \mathrm{m}$ & $14 / 16$ & $6 / 14$ & 0 & 0 & $10(3)$ & 0 & 3(3) & 0 & 1 \\
\hline Particles $1-4 \mu \mathrm{m}$ & $11 / 16$ & $1 / 11$ & 0 & 0 & $7(1)$ & 0 & 0 & 0 & 4 \\
\hline Particles $<1 \mu \mathrm{m}$ & $1 / 16$ & $0 / 1$ & 0 & 0 & 0 & 0 & 0 & 0 & 1 \\
\hline Air (Coriolis $\mu$ ) & $12 / 14$ & $4 / 12$ & 0 & 0 & $9(3)$ & 0 & $3(1)$ & 0 & 0 \\
\hline Drinking water & $8 / 11$ & $4 / 8$ & 0 & 0 & $3(1)$ & 0 & $5(3)$ & 0 & 0 \\
\hline Faecal droppings and surfaces & $28 / 48$ & $11 / 28$ & 0 & 0 & $16(9)$ & 0 & $9(2)$ & 0 & 3 \\
\hline \multicolumn{10}{|l|}{ Mixed animal market, Guangzhou ${ }^{f}$} \\
\hline \multicolumn{10}{|l|}{ Air (NIOSH sampler, site B1) } \\
\hline Particles $>4 \mu \mathrm{m}$ & $15 / 16$ & $5 / 15$ & 0 & 0 & $11(3)$ & $2(2)$ & 0 & 0 & 2 \\
\hline Particles $1-4 \mu \mathrm{m}$ & $9 / 16$ & $0 / 9$ & 0 & 0 & 7 & 0 & 0 & 0 & 2 \\
\hline Particles $<1 \mu \mathrm{m}$ & $1 / 16$ & $0 / 1$ & 0 & 0 & 0 & 0 & 0 & 0 & 1 \\
\hline \multicolumn{10}{|l|}{ Air (NIOSH sampler, site B2) } \\
\hline Particles $>4 \mu \mathrm{m}$ & $15 / 16$ & $4 / 15$ & 0 & 0 & $12(2)$ & $2(2)$ & o & 0 & 1 \\
\hline Particles $1-4 \mu \mathrm{m}$ & $11 / 16$ & $0 / 11$ & 0 & 0 & 7 & 0 & o & 0 & 4 \\
\hline Particles $<1 \mu \mathrm{m}$ & $3 / 16$ & $0 / 3$ & 0 & 0 & 0 & 0 & 0 & 0 & 3 \\
\hline Air (Coriolis $\mu$ ) & $14 / 14$ & $6 / 14$ & 0 & 0 & $10(4)$ & $3(2)$ & 0 & 0 & 1 \\
\hline Drinking water & $11 / 30$ & $3 / 11$ & $1(1)$ & 1 & $5(2)$ & 1 & 0 & 1 & 2 \\
\hline Faecal droppings and surfaces & $54 / 79$ & $15 / 54$ & $4(2)$ & 1 & $\begin{array}{c}32 \\
(12)\end{array}$ & 3 & 1 & 2 & $11(1)$ \\
\hline \multicolumn{10}{|l|}{ Retail market, Guangzhou } \\
\hline \multicolumn{10}{|l|}{ Air (NIOSH sampler) } \\
\hline Particles $>4 \mu \mathrm{m}$ & $10 / 10$ & $1 / 10$ & 0 & 0 & $5(1)$ & 2 & 1 & 0 & 2 \\
\hline Particles $1-4 \mu \mathrm{m}$ & $6 / 10$ & $0 / 6$ & 0 & 0 & 2 & 0 & 0 & 0 & 4 \\
\hline Particles $\ll 1 \mu \mathrm{m}$ & $1 / 10$ & $0 / 1$ & 0 & 0 & 0 & 0 & 0 & 0 & 1 \\
\hline Drinking water & $4 / 13$ & $0 / 4$ & 0 & 1 & 1 & 0 & 1 & 0 & 1 \\
\hline Faecal droppings and surfaces & $14 / 23$ & $1 / 14$ & 0 & 1 & $11(1)$ & 0 & 1 & 0 & 1 \\
\hline \multicolumn{10}{|c|}{ Wholesale market, Hong Kong SAR ${ }^{g}$} \\
\hline Air (NIOSH sampler) & $0 / 22$ & $0 / 0$ & 0 & 0 & 0 & 0 & 0 & 0 & 0 \\
\hline Air (Coriolis $\mu$ ) & $6 / 13$ & $0 / 6$ & 0 & 0 & 3 & 0 & 0 & 0 & 3 \\
\hline Faecal droppings and surfaces & $0 / 39$ & $0 / 0$ & 0 & 0 & 0 & 0 & o & 0 & 0 \\
\hline
\end{tabular}

HA: haemagglutinin; qRRT-PCR: quantitative real-time reverse transcription polymerase chain reaction.

a In the retail market in Guangzhou, sampling was conducted from January to October 2015; in the market in Hong Kong SAR, sampling was conducted in October and November in 2014 and in March, April, July, August, September and October in 2015.

Influenza A virus M gene was detected using qRRT-PCR.

The virus isolation rate was defined as the number of positive isolates after one passage in embryonic chicken eggs among influenza $A$ virus $M$ gene-positive samples.

d The $M$ gene-positive samples were further subtyped by qRRT-PCR using primers and probes for $\mathrm{H}_{5}, \mathrm{H}_{7}, \mathrm{H}_{9} \mathrm{HA}_{\text {. }}$

e The sampling site was located at the poultry holding area within the wholesale live poultry market (see site $A_{1}$ in the text).

f Sites B1 and B2 were two separate vendors' stalls within the mixed animal market.

g No drinking water was provided in the wholesale market in Hong Kong SAR. 
test) or the Coriolis sampler $(p=0.86,0.49$ and 0.32 , respectively).

In December 2014 and October 2015, neither air sampler detected the influenza $A$ virus $M$ gene. In December 2014, sampling was coincidentally performed on the market rest day (when the market was closed); all chickens were removed from the market but the environment had not yet been disinfected. In October 2015, sampling was performed the day after market closure. These results suggest that market closure may effectively reduce the viral load at the markets for a short time period.

\section{Site A2}

We performed air sampling while the de-feathering machine at site $\mathrm{A} 2$ was in operation (five samples) or not in use (three samples). While the machine was in operation, influenza $A$ virus $M$ gene was detected by qRRT-PCR from particles $>4 \mu \mathrm{m}$ in $5 / 5$ samples at $4,157-$ 28,929 copies/ $\mathrm{m}^{3}$ air (2/5 below LoQ) and from particles $1-4 \mu \mathrm{m}$ in $2 / 5$ samples (2/2 below LoQ); no viral RNA was detected from particles $<1 \mu \mathrm{m}$ (o/5 samples). $\mathrm{H}_{9}$ RNA was detected in $4 / 5$ samples and mixed $\mathrm{H}_{5} / \mathrm{H}_{9}$ RNA was detected in $1 / 5$ samples from particles $>4 \mu \mathrm{m}$; one $\mathrm{H}_{9} \mathrm{~N}_{2}$ virus was isolated from the air sample.

In contrast, influenza A virus $M$ gene was not detected in air sampled while the de-feathering machine was not in use (0/3 samples). At the same time, environmental swabs collected from the de-feathering machine were consistently positive for the $M$ gene by qRRT-PCR, regardless of whether the machine was in use or not. Overall, the results suggest that infectious influenza $A$ virus-laden particles can be generated during the defeathering process.

\section{Sampling at a mixed animal market in Guangzhou}

This mixed animal market sold live poultry, reptiles and mammals, although poultry were kept in a separate area. The predominant poultry species sold were aquatic birds (ducks and geese) and minor land-based poultries (pheasants, guinea fowls, chukar partridges, quails). Each vendor may have a few hundred birds of different species, which were kept in separate cages or pens of various sizes. There was no clear all-in/all-out policy or known routine market rest days.

NIOSH samplers were set up at two separate vendors' stalls (sites $B_{1}$ and $B_{2}$ ). At site $B_{1}$, influenza $A$ virus $M$ gene was detected by qRRT-PCR from particles $>4 \mu \mathrm{m}$ in $15 / 16$ samples at $6,179-1,650,000$ copies $/ m^{3}$ air (2/15 below LoQ), from particles $1-4 \mu \mathrm{m}$ in $9 / 16 \mathrm{sam}$ ples at 3,450-210,714 copies/m³ air (3/9 below LoQ) and from particles $<1 \mu \mathrm{m}$ in $1 / 16$ samples $(1 / 1$ below LoQ) (Figure 2). At site $B 2$, influenza $A$ virus $M$ gene was detected from particles $>4 \mu \mathrm{m}$ in $15 / 16$ samples at

TABLE 3

Influenza A virus isolation from samples with mixed H5, H7, H9 haemagglutinin subtypes from two live poultry markets in Guangzhou, China, July 2014-October 2015

\begin{tabular}{|c|c|c|c|c|}
\hline \multirow{2}{*}{ Sample type } & \multirow{2}{*}{ Sample ID } & \multirow{2}{*}{ Date } & \multicolumn{2}{|c|}{ HA subtype(s) detected } \\
\hline & & & In market samples by qRRT-PCR & After egg passage ${ }^{a}$ \\
\hline \multicolumn{5}{|l|}{ Wholesale market, Guangzhoub } \\
\hline \multirow{3}{*}{ NIOSH air sample } & GZ331 & Jun 2015 & $\mathrm{H}_{7}$ and $\mathrm{H}_{9}$ & $\mathrm{H}_{9}$ \\
\hline & GZ395 & Aug 2015 & $\mathrm{H}_{7}$ and $\mathrm{H}_{9}$ & $\mathrm{H}_{7}$ and $\mathrm{H}_{9}$ \\
\hline & $\mathrm{GZ} 437$ & Sep 2015 & $\mathrm{H}_{7}$ and $\mathrm{H}_{9}$ & $\mathrm{H} 9$ \\
\hline Coriolis $\mu$ air sample & GZ449 & Sep 2015 & $\mathrm{H}_{7}$ and $\mathrm{H}_{9}$ & $\mathrm{H} 9$ \\
\hline \multirow{3}{*}{ Drinking water } & GZ376 & Aug 2015 & $\mathrm{H}_{7}$ and $\mathrm{H}_{9}$ & $\mathrm{H}_{7}$ and $\mathrm{H}_{9}$ \\
\hline & $\mathrm{GZ} 378$ & Aug 2015 & $\mathrm{H}_{7}$ and $\mathrm{H}_{9}$ & $\mathrm{H}_{7}$ and $\mathrm{H}_{9}$ \\
\hline & GZ417 & Sep 2015 & $\mathrm{H}_{7}$ and $\mathrm{H}_{9}$ & $\mathrm{H} 9$ \\
\hline \multirow{2}{*}{ Faecal droppings } & GZ319 & Jun 2015 & $\mathrm{H}_{7}$ and $\mathrm{H}_{9}$ & $\mathrm{H}_{7}$ and $\mathrm{H}_{9}$ \\
\hline & GZ420 & Sep 2015 & $\mathrm{H}_{7}$ and $\mathrm{H}_{9}$ & $\mathrm{H} 9$ \\
\hline \multicolumn{5}{|l|}{ Mixed animal market, Guangzhouc } \\
\hline \multirow{2}{*}{ NIOSH air sample (site B1) } & GZo89 & Oct 2014 & $\mathrm{H}_{5}$ and $\mathrm{H}_{9}$ & $\mathrm{H}_{5}$ and $\mathrm{H}_{9}$ \\
\hline & $\mathrm{GZ184}$ & $\operatorname{Jan} 2015$ & $\mathrm{H}_{5}$ and $\mathrm{H}_{9}$ & $\mathrm{H}_{5}$ \\
\hline \multirow{2}{*}{ NIOSH air sample (site B2) } & GZ124 & Nov 2014 & $\mathrm{H}_{5}$ and $\mathrm{H}_{9}$ & $\mathrm{H}_{5}$ and $\mathrm{H}_{9}$ \\
\hline & $\mathrm{GZ187}$ & Jan 2015 & $\mathrm{H}_{5}$ and $\mathrm{H}_{9}$ & $\mathrm{H}_{5}$ and $\mathrm{H}_{9}$ \\
\hline \multirow{2}{*}{ Coriolis $\mu$ air sample (both sites $B_{1}$ and $B_{2}$ ) } & GZ259 & Mar 2015 & $\mathrm{H}_{5}$ and $\mathrm{H}_{9}$ & $\mathrm{H} 9$ \\
\hline & GZ289 & Apr 2015 & $\mathrm{H}_{5}$ and $\mathrm{H}_{9}$ & $\mathrm{H} 9$ \\
\hline
\end{tabular}

HA: haemagglutinin; qRRT-PCR: quantitative real-time reverse transcription polymerase chain reaction.

a A sample with copy numbers of influenza A virus $\mathrm{H}_{5}, \mathrm{H}_{7}$, or $\mathrm{H}_{9}$ genes (reduced threshold cycle (Ct) values by qRRT-PCR) higher than those of the original filed sample after egg propagation was considered positive by virus isolation.

b The sampling site was located at the poultry holding area within the wholesale live poultry market (see site $\mathrm{A}_{1}$ in the text).

Sites B1 and B2 were two separate vendors' stalls within the mixed animal market. 
3,590-204,286 copies/m³ air (4/15 below LoQ), from particles $1-4 \mu \mathrm{m}$ in $11 / 16$ samples at 3,050-20,857 copies $/ \mathrm{m}^{3}$ air (6/11 below LoQ) and from particles $<1 \mu \mathrm{m}$ in 3/16 sampling (3/3 below LoQ) (Figure 2 ).

$\mathrm{H}_{9}$ and mixed $\mathrm{H}_{5} / \mathrm{H}_{9}$ RNA were detected from the $\mathrm{M}$ gene-positive samples by qRRT-PCR. H9N2 $(n=6)$ and mixed $\mathrm{H}_{9} \mathrm{~N}_{2} / \mathrm{H}_{5} \mathrm{~N} 6(n=3)$ viruses were isolated from the fraction of particles $>4 \mu \mathrm{m}$, with isolation rates of 5/15 and 4/15 at sites B1 and B2, respectively (Tables 2 and 3$)$. Higher $M$ gene copy numbers ( $p=0.01$, MannWhitney test) and lower relative humidity $(p=0.04)$ were noted in the months when influenza virus was isolated in air sampled by the NIOSH sampler. Using the Coriolis sampler, influenza $A$ virus $M$ gene was detected from $14 / 14$ samples at 201-29,888 copies/ $\mathrm{m}^{3}$ air (1/14 below LoQ), which were subsequently confirmed as $\mathrm{H}_{9}$ or mixed $\mathrm{H}_{5} / \mathrm{H}_{9}$ subtypes. Six $\mathrm{H}_{9} \mathrm{~N}_{2}$ viruses were isolated from 14 air samples collected by the Coriolis sampler (Table 2).

Influenza A viral RNA was detected from 60\% (65/109) environmental swabs (water, faecal droppings and surfaces), with an isolation rate of $18 / 65 . \mathrm{H}_{9}$ (37/65), $\mathrm{H}_{5}$ (5/65), $\mathrm{H}_{7}(2 / 65)$, mixed $\mathrm{H}_{5} / \mathrm{H}_{9}(4 / 65)$, mixed $\mathrm{H}_{5} / \mathrm{H}_{7}$ (3/65), mixed $\mathrm{H}_{7} / \mathrm{H}_{9}(1 / 65)$ or non $-\mathrm{H}_{5} / \mathrm{H}_{7} / \mathrm{H}_{9}(13 / 65)$

\section{FIGURE 2}

Influenza $\mathrm{A}$ virus $\mathrm{M}$ gene copy number from particles in air sampled at two separate vendors in a mixed animal market in Guangzhou city, China, July 2014-October 2015

Site B1
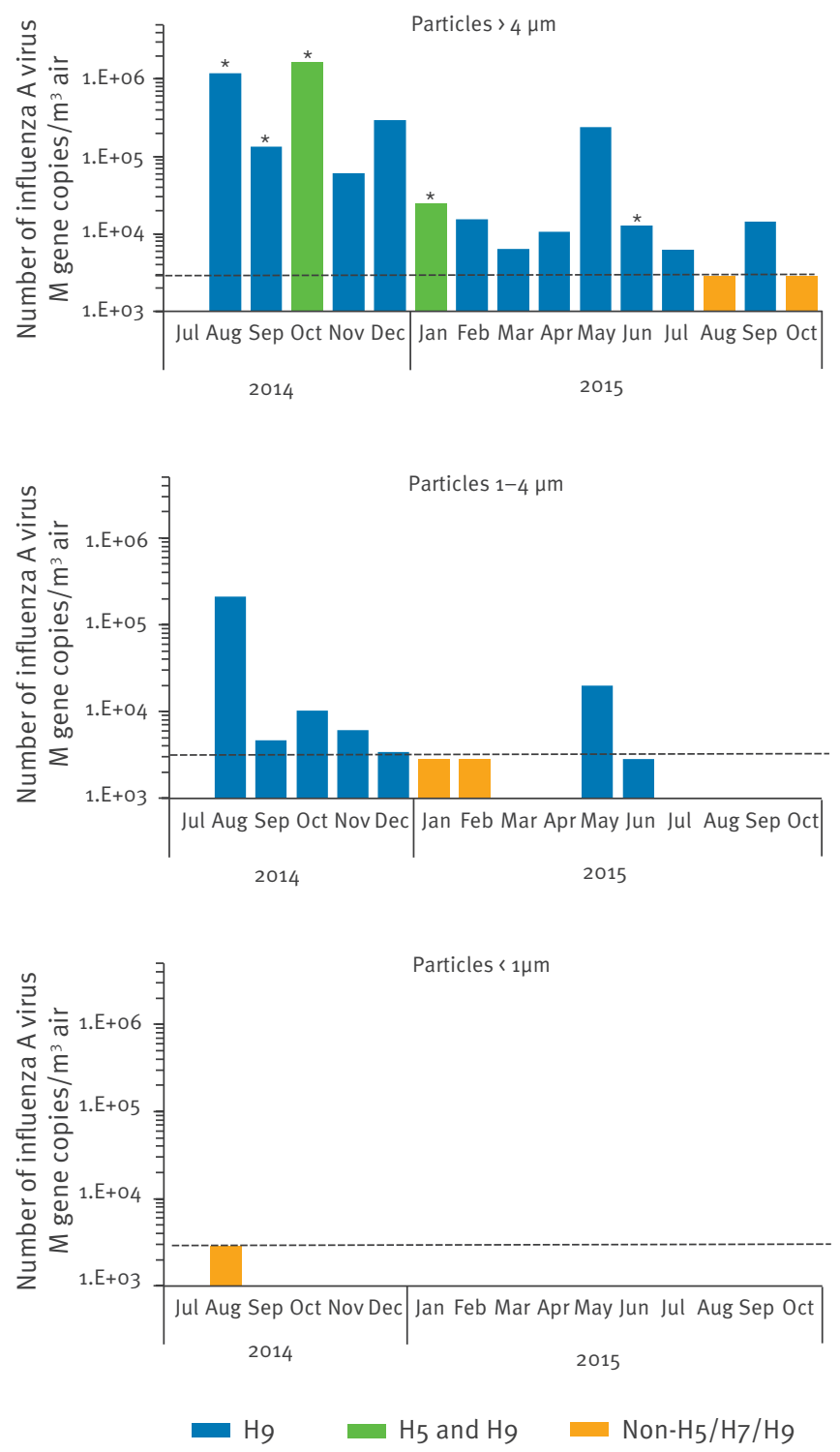

Site B2
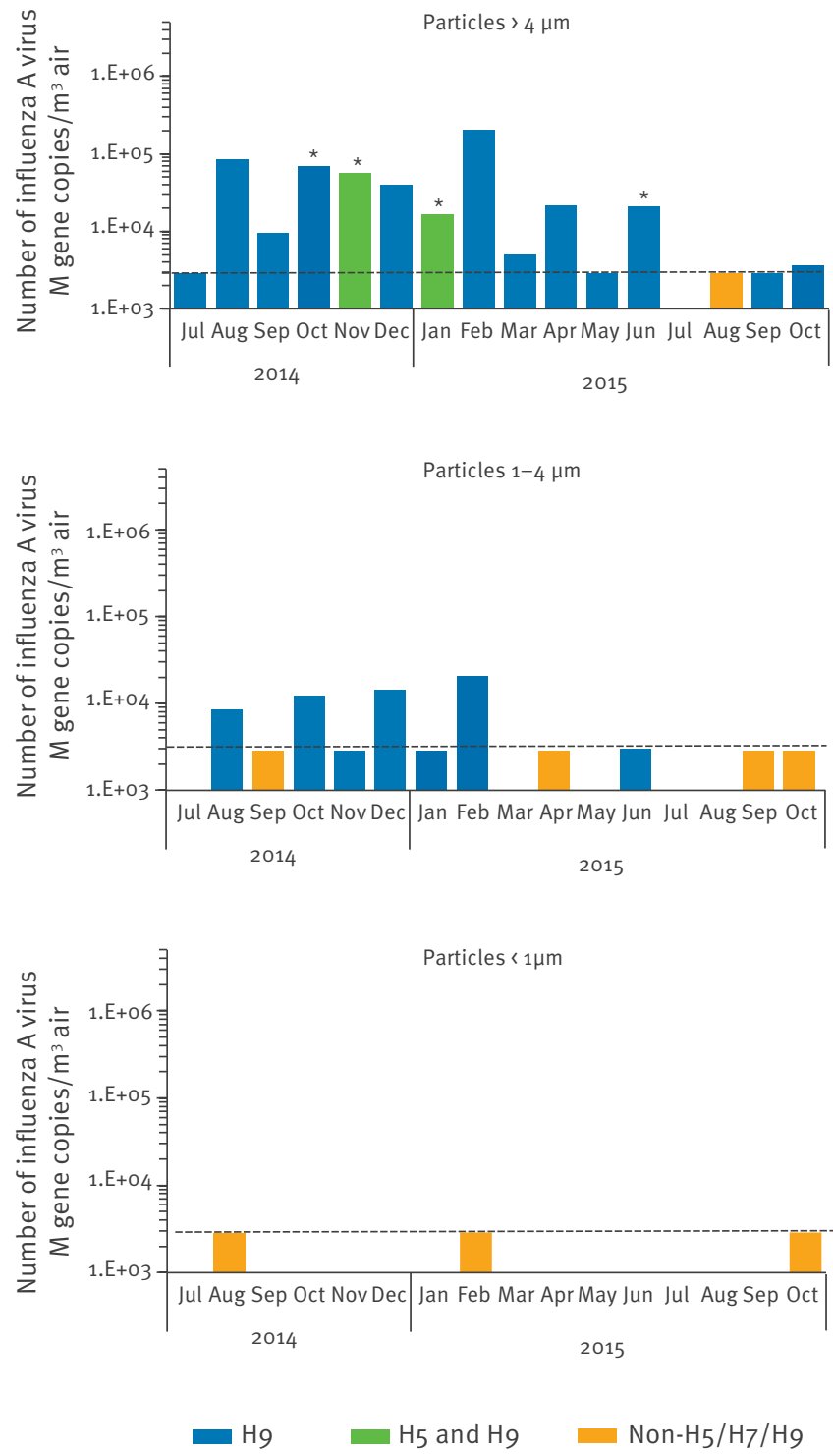

The quantity and subtypes of influenza virus-laden particles at particle sizes at>4, 1-4 and 1 H m detected in the air using a NIOSH bioaerosol sampler at two sampling sites (sites B1 and B2) within the market are shown. The horizontal dotted lines indicate the linear range of quantification for influenza A virus $M$ gene by quantitative real-time reverse transcription polymerase chain reaction (qRRT-PCR) assay. Samples in which virus was isolated after one passage in embryonated eggs are indicated by an asterisk (*). 
were further identified by qRRT-PCR (Table 2). $\mathrm{H}_{9} \mathrm{~N}_{2}$ $(n=14), \mathrm{H}_{5} \mathrm{~N} 6(n=2), \mathrm{H}_{5} \mathrm{~N}_{2}(n=1)$, and $\mathrm{H}_{4} \mathrm{~N} 8(n=1)$ viruses were isolated. The subtypes detected in samples obtained using the NIOSH bioaerosol sampler and in environmental swabs were not statistically different ( $p=0.27$, Fisher's exact test). Overall, five $\mathrm{H}_{5} \mathrm{~N} 6$ viruses (three mixed with $\mathrm{H}_{9} \mathrm{~N}_{2}$ ) and one $\mathrm{H}_{5} \mathrm{~N}_{2}$ virus were isolated from the air and environmental samples. The $\mathrm{H}_{5}$ isolates belonged to clade 2.3.4.4 with 94.0-99.0\% homology to the human $\mathrm{H}_{5} \mathrm{~N} 6$ virus $\mathrm{A} /$ Guangzhou/39715/2014 (GISAID: EPI_ISL_180669) [15].

\section{Sampling at a retail market in Guangzhou}

This retail market had 10 stalls that sold live poultry. Sampling was performed in one stall of $4 \mathrm{~m}^{2}$, which held 30-50 birds daily (co-housed chickens, ducks, pigeons, geese and quails). There were no clear all-in/ all-out policy or known regular market rest days for disinfection. Sampling at the retail market was conducted from January to October 2015.

Using the NIOSH sampler, influenza A virus $M$ gene was detected by qRRT-PCR from particles $>4 \mu \mathrm{m}$ in $10 / 10$ samples at $9,243-455,714$ copies $/ \mathrm{m}^{3}$ air $(6 / 10$ below LoQ), particles 1-4 $\mu \mathrm{m}$ in 6/10 samples at 3,130-14,071 copies/m $\mathrm{m}^{3}$ air ( $4 / 6$ below LoQ) and particles $<1 \mu \mathrm{m}(1 / 10$ samples, 1/1 below LoQ). H9 RNA was predominantly detected while mixed $\mathrm{H}_{7} / \mathrm{H}_{9}$ and $\mathrm{H}_{5} / \mathrm{H}_{9}$ RNA were also detected by qRRT-PCR. One $\mathrm{H}_{9} \mathrm{~N}_{2}$ virus was isolated from particles $>4 \mu \mathrm{m}$ among 10 samples positive for influenza $A$ virus $M$ gene.

The viral $M$ gene was detected in 18/36 environmental swabs from drinking water, faecal droppings and surfaces; further subtyping identified $\mathrm{H}_{9}$ RNA (12/18), $\mathrm{H}_{7}$ RNA (2/18), mixed $\mathrm{H}_{7} / \mathrm{H}_{9}$ RNA (2/18) and non- $\mathrm{H}_{5} / \mathrm{H}_{7} / \mathrm{H}_{9}$ RNA (2/18), with one H9N2 virus isolated (Table 2$)$. The subtypes detected by qRRT-PCR from the environmental swabs were not significantly different from those detected in the air samples obtained using the NIOSH sampler $(p=0.45$, Fisher's exact test).

\section{Sampling at a wholesale poultry market in Hong Kong SAR}

This wholesale poultry market served as a temporary holding site for chickens imported from mainland China or raised locally. The chickens stayed for no longer than 48 hours until sold to retail markets, with a firstin/ first-out policy, segregation and strict biosecurity measures. Since 2013, chickens imported from mainland China and those raised locally have been housed separately at different locations.

Sampling was conducted in the area holding local poultry in October and November in 2014 as well as in March, April, July, August, September and October in 2015. At each sampling, NIOSH $(n=2-3)$ and Coriolis ( $n=1-2)$ samplers were set up and there were varying numbers of chickens (between 50 and 500) in the holding area. Influenza $A$ virus $M$ gene was not detected by qRRT-PCR in any of the $22 \mathrm{NIOSH}$ samples but was detected in 6/13 Coriolis samples at 203-470 copies/ $\mathrm{m}^{3}$ air (3/6 below LoQ). Further subtyping identified $\mathrm{H}_{9}(3 / 6)$ or non- $\mathrm{H}_{5} / \mathrm{H}_{7} / \mathrm{H}_{9}$ (3/6) RNA from the $M$ genepositive samples (Table 2). Furthermore, none of the 39 environmental swabs were positive for the influenza $A$ virus $M$ gene (Table 2 ). The quantity of influenza $A$ virus-laden particles in the air by the Coriolis sampler at this wholesale live poultry market in Hong Kong SAR (203-470 copies/m³ $/ \mathrm{M}$ gene-positive rate: 6/13, 3/6 below LoQ) was lower than that for the wholesale live poultry market (310-21,413 copies/m³ $/ \mathrm{m}^{3}$ gene-positive rate: $12 / 14)$ or the mixed animal market (201-29,888 copies $/ \mathrm{m}^{3}, M$ gene-positive rate: $14 / 14,1 / 14$ below LoQ) in Guangzhou city.

\section{Genetic analysis of $\mathrm{H} 9 \mathrm{~N} 2$ viruses isolated from} the live poultry markets

The $\mathrm{H}_{9} \mathrm{~N} 2$ virus was the most frequently isolated subtype from the markets in Guangzhou we sampled, with a total of 58 isolates of $\mathrm{H}_{9}, \mathrm{H}_{9} / \mathrm{H}_{7}$, or $\mathrm{H}_{9} / \mathrm{H}_{5}$ subtypes (Table 2). We performed a phylogenetic analysis of the $\mathrm{HA}$ gene of 46 selected $\mathrm{H}_{9} \mathrm{~N}_{2}$ viruses isolated from the wholesale market (10 air samples, 15 environmental swabs) and the mixed animal market (10 air samples, 11 environmental swabs) in Guangzhou city. The H9N2 viruses isolated from the air and environment from the same market were genetically related. Furthermore, the $\mathrm{H}_{9} \mathrm{~N}_{2}$ viruses isolated from the wholesale and the mixed animal markets were separately clustered into two clades (Figure 3).

The $\mathrm{H}_{9} \mathrm{~N}_{2}$ viruses isolated in the wholesale market shared high nucleotide homology (93.5-100\%) and all clustered with the $\mathrm{A} /$ chicken/Zhejiang/HJ/2007 virus (G57 genotype), which evolved from A/Duck/Hong Kong/Y280/1997 (Y280 genotype) and has become dominant among chickens in China since 2010 [16]. At the mixed animal market, where minor land poultry were sold, the majority of $\mathrm{H}_{9} \mathrm{~N} 2$ isolates (17/19) clustered together with the the A/quail/Hong Kong/ $\mathrm{G} 1 / 1997$ (G1-like) virus, with high nucleotide homology (91.4-99.9\%), except for two isolates collected in January 2015 by the NIOSH and Coriolis air samplers, which were clustered with the $\mathrm{G}_{57}$ genotype. The G1-like $\mathrm{H}_{9} \mathrm{~N}_{2}$ viruses have been commonly detected in China since the late 1990 s from minor poultry species such as quails and chukar partridges $[17,18]$.

\section{Discussion}

Influenza viruses are transmitted via different but nonmutually exclusive modes [4]. Infections are mediated via virus-laden particles of various sizes that confer fomite, droplet or airborne transmission [19-21], but the modes of transmission for human zoonotic infections by avian influenza viruses at the human-poultry interface are not well defined. In our study, we determined the quantity, viability, subtype and size of influenza virus-laden particles in the air at three types of live poultry markets in Guangzhou city. Although our study is limited to a small number of markets in 


\section{FIGURE 3}

Phylogenetic analysis of the haemagglutinin gene of avian influenza $\mathrm{A}(\mathrm{H} 9 \mathrm{~N} 2)$ viruses isolated from a wholesale market and a mixed animal market in Guangzhou, China, July 2014-October $2015(\mathrm{n}=46)$

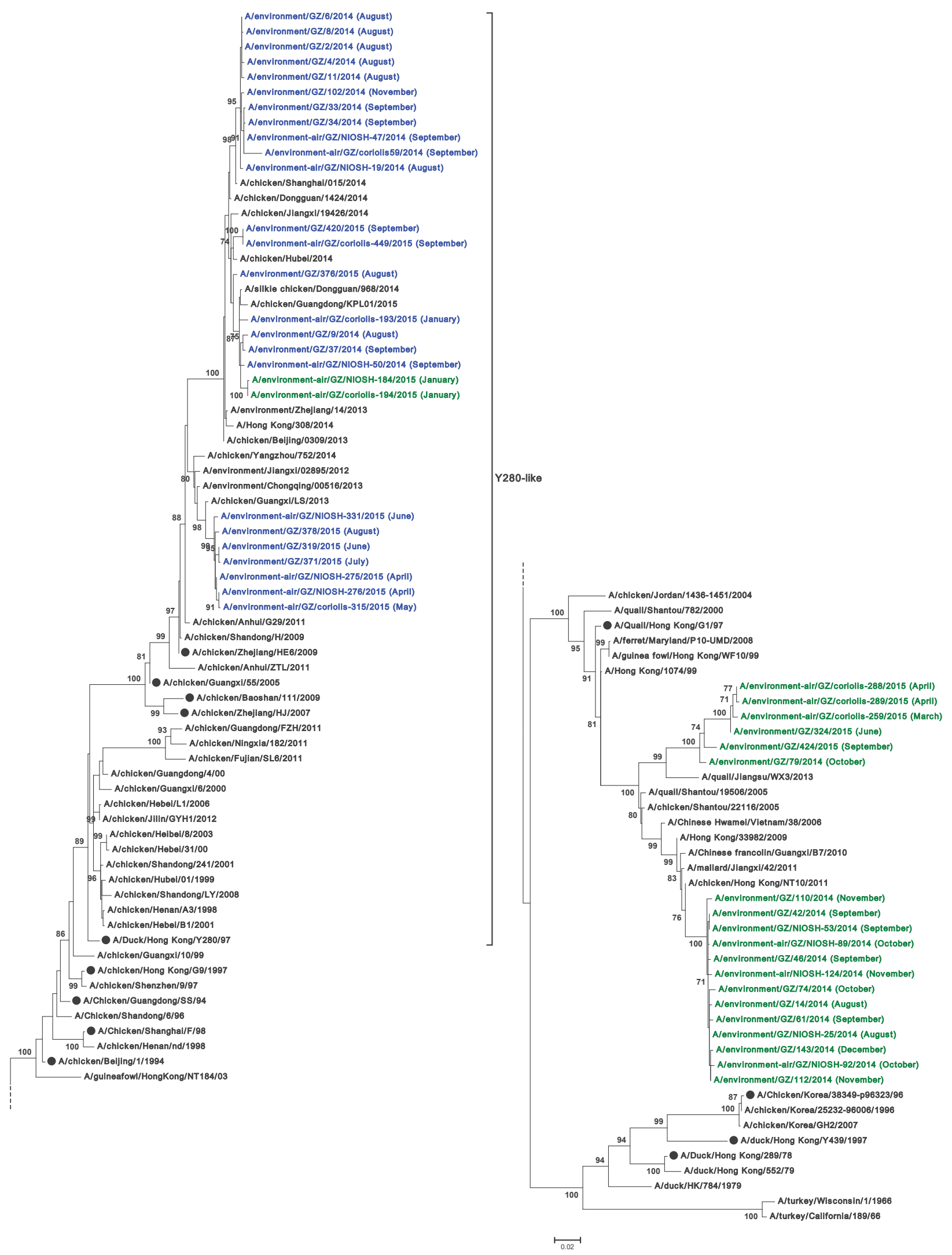

HA: haemagglutinin; G1-like: A/quail/Hong Kong/G1/97-like H9N2 virus; Y280-like: A/Duck/Hong Kong/Y280/97-like H9N2 virus.

The coding sequence of the HA gene (1,093 nucleotides, 115-1,207 nucelotides from ATG) was aligned for the phylogenetic analysis. H9N2 viruses isolated from the wholesale market and mixed animal market in Guangzhou are shown in blue and green, respectively. The black circles indicate the representative strains of distinct $\mathrm{H} 9$ lineages and the vaccine strains.

The phylogenetic tree was constructed by maximum likelihood method with bootstrap analysis $(n=1,000)$ using MEGA (version 6.0) software. 
Guangzhou city and Hong Kong SAR and the results should be interpreted with caution, we show that viral RNA or viable avian influenza viruses of $\mathrm{H}_{5}, \mathrm{H}_{7}$ and $\mathrm{H}_{9}$ subtypes with human zoonotic infection potential are readily detectable in the air, suggesting the feasibility of airborne transmission of avian influenza viruses at the human-poultry interface. Furthermore, human activities, such as operation of de-feathering machines commonly used at live poultry markets in China, may facilitate generation of viable virus-laden particles in the air. In contrast, the negative air sampling results obtained at the wholesale market in Guangzhou on or after market closure day suggest that appropriate interventions may reduce the viral load effectively in the environment. While poultry markets are not common in Europe, the result is consistent with the detection of influenza viral RNA in the air at poultry farms sampled during avian influenza outbreaks in the Netherlands [22]. Our study provides experimental evidence showing that viable avian influenza viruses can be detected in the air where live poultry are kept, which is consistent with previous reports that detected viral RNA and infectious influenza viruses at swine barns or at live pig markets in the United States [23,24]. Although it is difficult to compare our results with those reported previously due to differences in the air samplers used, the concentrations of viral RNA we detected in the air at the live poultry markets were comparable with those detected at the swine barns in the United States in 2011 [24].

Our results suggest that poultry workers in the live poultry markets are constantly exposed to high viral loads in the air and the environment, but human symptomatic infections caused by avian influenza viruses in this population remain uncommon. Excluding the samples collected at the slaughtering area of the Guangzhou wholesale market (site A2) and from the live poultry market in Hong Kong, using the NIOSH bioaerosol sampler, viral RNA or viable virus was identified predominantly from particles > $4 \mu \mathrm{m}$ (16 viable isolates of 58 samples collected), occasionally from 1-4 $\mu \mathrm{m}$ (1/58), and none from particles $<1 \mu \mathrm{m}$ (0/58). Previous studies that analysed particle deposition suggest particles $<3 \mu \mathrm{m}$ are more likely to deposit in the deep lungs [25] where avian influenza viruses with binding specificity for a2,3-linked sialic acids preferentially replicate [26]. In addition, seroepidemiological studies have reported a limited number of cases with low levels of neutralising antibody titres using hemagglutination inhibition assay or neutralisation assay [2729]; however, the mechanism of cross-protection may be via non-neutralising antibodies or T-cell response. Further studies are needed to evaluate the percentage of subclinical infections and to assess the crossprotective adaptive immune response between poultry workers and the general population.

The $\mathrm{H}_{9} \mathrm{~N} 2$ avian influenza virus ubiquitously present among land-based poultry in China and other countries [30] was the predominant subtype detected from the air and environmental samples in our study. Genetically diverse $\mathrm{H}_{9} \mathrm{~N}_{2}$ viruses have been shown to possess human-like receptor binding specificity [31], transmission potential among ferrets [32] and have provided the internal genes for the $\mathrm{H}_{7} \mathrm{~N} 9$ or $\mathrm{H}_{10} \mathrm{~N} 8$ viruses that have caused fatal human infections since 2013 [33]. Unlike highly pathogenic viruses of $\mathrm{H}_{5}$ subtype that replicate systematically and cause high mortality, the low pathogenic $\mathrm{H}_{9} \mathrm{~N}_{2}$ and $\mathrm{H}_{7} \mathrm{~N}_{9}$ viruses generally do not cause apparent clinical signs in infected poultry [30,34]; this poses a challenge in identifying the infected birds for infection control and facilitates the spread of the $\mathrm{H}_{9} \mathrm{~N}_{2}$ and $\mathrm{H}_{7} \mathrm{~N}_{9}$ viruses in live poultry markets. $\mathrm{H}_{9} \mathrm{~N}_{2}$ and $\mathrm{H}_{7} \mathrm{~N} 9$ viruses are known to replicate more efficiently in the respiratory tract than the gastrointestinal tract of the land-based poultry $[34,35]$, and the highly prevalent $\mathrm{H}_{9} \mathrm{~N}_{2}$ virus has been the dominant subtype detected in the air at the poultry markets, as shown in the present study. Determining the viral loads and subtypes from oropharyngeal and cloacal swabs from different poultry species may help to understand the effect of viral respiratory tropism versus the quantity of virusladen particles released in the air. We also observed segregation of species-adapted $\mathrm{H}_{9} \mathrm{~N}_{2}$ lineages at different markets; further studies should investigate if the segregation is due to repeated re-introduction of a species-adapted virus as a result of selling different species at different markets or if insufficient cleaning of the environment facilitated the persistence and segregation of the $\mathrm{H}_{9} \mathrm{~N}_{2}$ virus.

Among the three different types live poultry markets in Guangzhou, we noted higher virus isolation rates from air samples collected at the wholesale market and the mixed poultry market than that of the retail market, suggesting the number of poultry sold on site may affect the quantity of viable virus detected in the air. Cleaning practices, such as the market rest day, may have an impact as well. In addition, we noted a higher detection rate and isolation rate from particle $>4 \mu \mathrm{m}$, regardless of the viral subtype, suggesting that there is no correlation between avian influenza A subtype and virus detection at specific particle sizes. Since the subtypes detected in the air correlate well with the subtypes detected from the environment (water, faecal droppings and surfaces), the prevalence of a subtype in poultry (e.g. H9N2) may be a major contributing factor to the subtype detected in the air; however, other factors including viral tropism in poultry should also be considered. Temperature and relative humidity can affect viral viability and the sizes of virus-laden particles in the air. However, we did not observe a strong impact of temperature and humidity on viral detection at specific particle sizes; a longer observation period and/or frequent sampling will be needed to address this question.

Taken together, our results indicate the possibility of airborne transmission for avian influenza $A$ viruses and may explain some human cases who appear to have acquired $\mathrm{H}_{7} \mathrm{~N} 9$ infection by visiting live poultry 
markets but without direct or indirect contact to poultry [8]. Furthermore, the observation that known zoonotic infections have been in people with transient contact with, or passing the vicinity of live poultry markets rather than those working within them, who are clearly exposed to avian influenza viruses on almost a daily basis - suggests a role for host susceptibility as one of the key determinants of zoonotic infection.

\section{Acknowledgements}

We acknowledge the authors, originating and submitting laboratories of the sequences from GISAID's EpiFlu Database (see Table 1). All submitters of data may be contacted directly via the GISAID website (www.gisaid.org).

We thank the Agriculture, Fisheries and Conservation Department from the Government of Hong Kong SAR for the access to the wholesale live poultry market in Hong Kong. This study was supported by HMRF (\#RRG01) and Theme-based Research Scheme (Project No. T11$705 / 14 N$ ) from the Government of Hong Kong SAR, Contract HHSN272201400006C from the NIAID, NIH, AXA Research Award, HKU Seed Funding for Basic Research, and Science and Technology Planning Project of Guangzhou City, China (2014J4100091, 2013B020307006, 2013B020224004).

The findings and conclusions in this report are those of the authors and do not necessarily represent the views of the National Institute for Occupational Safety and Health.

\section{Conflict of interest}

None declared.

\section{Authors' contributions}

JZ, CK, JSMP, JW and HY participated in the study design; JZ, $X Z, G H, L Z, Y S, D G$ and $X Z$ performed sampling at the poultry markets; JZ and XZ performed the sequence analysis; JZ, XZ, MK, JL, BJC, WGL, JSMP, JW and HY interpreted and analysed the data; IZ, JSMP and HY wrote the manuscript. All authors contributed to the study and have read and approved the manuscript.

\section{References}

1. Neumann G, Kawaoka Y. Transmission of influenza $A$ viruses.Virology. 2015;479-480:234-46. DOI: 10.1016/j. virol.2015.03.009

2. de Graaf M, Fouchier RA. Role of receptor binding specificity in influenza A virus transmission and pathogenesis.EMBO J. 2014;33(8):823-41. DOI: 10.1002/embj.201387442

3. Jones RM, Brosseau LM. Aerosol transmission of infectious disease.J Occup Environ Med. 2015;57(5):501-8. DOI: 10.1097/ JOM.0000000000000448

4. Tellier R. Review of aerosol transmission of influenza $A$ virus.Emerg Infect Dis. 2006;12(11):1657-62. DOI: 10.3201/ eid1211.060426

5. Lowen AC, Steel J. Roles of humidity and temperature in shaping influenza seasonality.J Virol. 2014;88(14):7692-5. DOI: $10.1128 / \mathrm{JVI} .03544^{-13}$

6. World Health Organization (WHO). Influenza at the humananimal interface. Summary and assessment as of 14 December 2015. Geneva: WHO; 2015. Available from: http://www.who.int/ influenza/human_animal_interface/Influenza_Summary_IRA_ HA_interface_14_Dec_2015.pdf?ua=1

7. Peiris JSM, Cowling BJ, Wu JT, Feng L, Guan Y, Yu H, et al. Interventions to reduce zoonotic and pandemic risks from avian influenza in Asia. Lancet Infect Dis. 2016;16(2):252-8. DOI: 10.1016/S1473-3099(15)00502-2
8. Liu B, Havers F, Chen E, Yuan Z, Yuan H, Ou J, et al. Risk factors for influenza $\mathrm{A}\left(\mathrm{H}_{7} \mathrm{Ng}\right)$ disease--China, 2013. Clin Infect Dis. 2014;59(6):787-94. DOI: 10.1093/cid/ciu423

9. Kang M, He J, Song T, Rutherford S, Wu J, Lin J, et al. Environmental Sampling for Avian Influenza $\mathrm{A}\left(\mathrm{H}_{7} \mathrm{Ng}\right)$ in Live-Poultry Markets in Guangdong, China. PLoS One. 2015;10(5):e0126335. DOI: 10.1371/journal.pone.0126335

10. Indriani R, Samaan G, Gultom A, Loth L, Irianti S, Adjid $R$, et al. Environmental sampling for avian influenza virus $A\left(\mathrm{H}_{5} \mathrm{~N}_{1}\right)$ in live-bird markets, Indonesia. Emerg Infect Dis. 2010;16(12):1889-95. DOI: 10.3201/eid1612.100402

11. Lindsley WG, Schmechel D, Chen BT. A two-stage cyclone using microcentrifuge tubes for personal bioaerosol sampling.J Environ Monit. 2006;8(11):1136-42. DOI: 10.1039/b609083d

12. World Health Organization (WHO). WHO information for molecular diagnosis of influenza virus - update. Geneva: WHO; Mar 2014. Available from: http://www.who.int/influenza/ gisrs_laboratory/molecular_diagnosis/en/

13. Hoffmann E, Stech J, Guan Y, Webster RG, Perez DR. Universal primer set for the full-length amplification of all influenza A viruses.Arch Virol. 2001;146(12):2275-89. DOI: 10.1007/ s007050170002

14. Bogner P, Capua I, Lipman DJ, Cox NJ. others. A global initiative on sharing avian flu data.Nature. 2006;442(7106):981. DOI: $10.1038 / 442981 a$

15. Smith GJ, Donis RO. World Health Organization/World Organisation for Animal Health/Food and Agriculture Organization (WHO/OIE/FAO) $\mathrm{H}_{5}$ Evolution Working Group. Nomenclature updates resulting from the evolution of avian influenza $\mathrm{A}\left(\mathrm{H}_{5}\right)$ virus clades 2.1.3.2a, 2.2.1, and 2.3.4 during 2013-2014. Influenza Other Respi Viruses. 2015;9(5):271-6. DOI: 10.1111/irv.12324

16. Pu J, Wang S, Yin Y, Zhang G, Carter RA, Wang J, et al. Evolution of the $\mathrm{H} 9 \mathrm{~N} 2$ influenza genotype that facilitated the genesis of the novel $\mathrm{H}_{7} \mathrm{~N} 9$ virus. Proc Natl Acad Sci USA. 2015;112(2):548-53. DOI: 10.1073/pnas.1422456112

17. Guan Y, Shortridge KF, Krauss S, Webster RG. Molecular characterization of $\mathrm{H}_{9} \mathrm{~N}_{2}$ influenza viruses: were they the donors of the "internal" genes of $\mathrm{H}_{5} \mathrm{~N}_{1}$ viruses in Hong Kong?Proc Natl Acad Sci USA. 1999;96(16):9363-7. DOI: 10.1073/pnas.96.16.9363

18. Xu KM, Smith GJ, Bahl J, Duan L, Tai H, Vijaykrishna D, et al. The genesis and evolution of $\mathrm{H}_{9} \mathrm{~N} 2$ influenza viruses in poultry from southern China, 2000 to 2005. J Virol. 2007;81(19):10389401. DOI: 10.1128/JVI.00979-07

19. Cowling BJ, Ip DK, Fang VJ, Suntarattiwong P, Olsen SJ, Levy J, et al. Aerosol transmission is an important mode of influenza A virus spread. Nat Commun. 2013;4:1935. DOI: 10.1038/ ncomms2922

20. Milton DK, Fabian MP, Cowling BJ, Grantham ML, McDevitt JJ. Influenza virus aerosols in human exhaled breath: particle size, culturability, and effect of surgical masks.PLoS Pathog. 2013;9(3):e1003205. DOI: 10.1371/journal.ppat.1003205

21. Lindsley WG, Noti JD, Blachere FM, Thewlis RE, Martin $S B$, Othumpangat $S$, et al. Viable influenza $A$ virus in airborne particles from human coughs. J Occup Environ Hyg. 2015;12(2):107-13. DOI: 10.1080/15459624.2014.973113

22. Jonges M, van Leuken J, Wouters I, Koch G, Meijer A, Koopmans M. Wind-Mediated Spread of Low-Pathogenic Avian Influenza Virus into the Environment during Outbreaks at Commercial Poultry Farms.PLoS One. 2015;10(5):e0125401. DOI: 10.1371/ journal.pone.0125401

23. Choi MJ, Torremorell M, Bender JB, Smith K, Boxrud D, Ertl JR, et al. Live animal markets in Minnesota: a potential source for emergence of novel influenza $A$ viruses and interspecies transmission. Clin Infect Dis. 2015;61(9):1355-62. DOI: 10.1093/ cid/civ618

24. Corzo CA, Culhane M, Dee S, Morrison RB, Torremorell M. Airborne detection and quantification of swine influenza a virus in air samples collected inside, outside and downwind from swine barns.PLoS One. 2013;8(8):e71444. DOI: 10.1371/ journal.pone.0071444

25. Carvalho TC, Peters JI, Williams RO. Influence of particle size on regional lung deposition--what evidence is there? Int J Pharm. 2011;406(1-2):1-10.

26. Shinya K, Ebina M, Yamada S, Ono M, Kasai N, Kawaoka Y Avian flu: influenza virus receptors in the human airway. Nature. 2006;440(7083):435-6.

27. Khan SU, Anderson BD, Heil GL, Liang S, Gray GC. A Systematic Review and Meta-Analysis of the Seroprevalence of Influenza $A\left(\mathrm{H}_{9} \mathrm{~N}_{2}\right)$ Infection Among Humans.J Infect Dis. 2015;212(4):5629. DOI: $10.1093 /$ infdis/jiv109

28. Yang P, Ma C, Shi W, Cui S, Lu G, Peng X, et al. A serological survey of antibodies to $\mathrm{H}_{5}, \mathrm{H}_{7}$ and $\mathrm{H}_{9}$ avian influenza viruses 
amongst the duck-related workers in Beijing, China. PLoS One. 2012;7(11):e50770. DOI: 10.1371/journal.pone.0050770

29. Nasreen S, Uddin Khan S, Azziz-Baumgartner E, Hancock K, Veguilla V, Wang D, et al. Seroprevalence of antibodies against highly pathogenic avian influenza $A\left(\mathrm{H}_{5} \mathrm{~N}_{1}\right)$ virus among poultry workers in Bangladesh, 2009. PLoS One. 2013;8(9):e73200. DOI: 10.1371/journal.pone.0073200

30. Sun Y, Liu J. H9N2 influenza virus in China: a cause of concern. Protein Cell. 2015;6(1):18-25. DOI: 10.1007/S13238-014-0111-7

31. Matrosovich MN, Krauss S, Webster RG. H9N2 influenza A viruses from poultry in Asia have human virus-like receptor specificity.Virology. 2001;281(2):156-62. DOI: 10.1006/ viro.2000.0799

32. Li X, Shi J, Guo J, Deng G, Zhang Q, Wang J, et al. Genetics, receptor binding property, and transmissibility in mammals of naturally isolated $\mathrm{H}_{9} \mathrm{~N}_{2}$ Avian Influenza viruses. PLoS Pathog. 2014;10(11):e1004508. DOI: 10.1371/journal.ppat.1004508

33. Su S, Bi Y, Wong G, Gray GC, Gao GF, Li S. Epidemiology, Evolution, and Recent Outbreaks of Avian Influenza Virus in China.J Virol. 2015;89(17):8671-6. DOI: 10.1128/JVI.01034-15

34. Pantin-Jackwood MJ, Miller PJ, Spackman E, Swayne DE, Susta $L$, Costa-Hurtado $M$, et al. Role of poultry in the spread of novel $\mathrm{H}_{7} \mathrm{~N} 9$ influenza virus in China. J Virol. 2014;88(10):538190. DOI: $10.1128 /$ JVI.03689-13

35. Makarova NV, Ozaki H, Kida H, Webster RG, Perez DR.

Replication and transmission of influenza viruses in

Japanese quail.Virology. 2003;310(1):8-15. DOI: 10.1016/ S0042-6822(03)00094-1

36. Squires RB, Noronha J, Hunt V, García-Sastre A, Macken $\mathrm{C}$, Baumgarth $\mathrm{N}$, et al. Influenza research database: an integrated bioinformatics resource for influenza research and surveillance. Influenza Other Respi Viruses. 2012;6(6):404-16. DOI: $10.1111 /$ j.1750-2659.2011.00331.x

\section{License and copyright}

This is an open-access article distributed under the terms of the Creative Commons Attribution (CC BY 4.0) Licence. You may share and adapt the material, but must give appropriate credit to the source, provide a link to the licence, and indicate if changes were made.

This article is copyright of the authors, 2016. 